\title{
LITERATURA MISIONAL Y HAGIOGRAFÍA EN EL SIGLO XIX: JACINTO JUANMARTÍ, UN MISIONERO JESUITA EN FILIPINAS (1833-1897)*
}

\author{
POR \\ MARÍA AguileRA FERNÁNDEZ ${ }^{1}$ \\ Universidad Autónoma de Barcelona
}

\begin{abstract}
RESUMEN
Este estudio reconstruye la vida de Jacinto Juanmartí, un misionero jesuita que laboró en Filipinas durante la segunda mitad del siglo XIX, mediante una biografía manuscrita y decenas de cartas escritas por él mismo y sus compañeros. A través de esta vida memorable se manifiestan dos aspectos novedosos en el siglo XIX. En primer lugar, el florecimiento de una nueva etapa misional, donde la fiebre humanitaria igualó al desvelo por la salvación de las almas. En segundo lugar, la aparición de diferencias significativas en la literatura misional y las hagiografías jesuitas respecto a la Época Moderna, pese a la persistencia del mensaje enaltecedor de la Compañía de Jesús.
\end{abstract}

PALABRAS CLAVE: literatura misional; hagiografía; jesuita; Filipinas; Mindanao; Tamontaca; siglo XIX; Historia de la Iglesia.

\section{MISSIONARY LITERATURE AND HAGIOGRAPHY IN THE NINETEENTH CENTURY: JACINTO JUANMARTÍ, A JESUIT MISSIONARY IN PHILIPPINES (1833-1897)}

\begin{abstract}
This study reconstructs the life of Jacinto Juanmartí, a Jesuit missionary who worked in the Philippines the second half of the nineteenth century, by a handwritten biography and dozens of letters written by himself and his colleagues. Through this memorable life two novel aspects in the nineteenth century are manifest. First, the blossoming of a new missionary stage, where humanitarian fever equaled anxiety for the salvation of souls. Second, the emergence of significant differences in Jesuit missionary literature and hagiographies regarding the Modern Age, despite the persistence of the uplifting message of the Society of Jesus.
\end{abstract}

KEY WORDS: Missionary Literature; Hagiography; Jesuit; Philippines; Mindanao; Tamontaca; Nineteenth Century; Church's History.

CÓMO CITAR ESTE ARTíCULO / CITATION: Aguilera Fernández, M. 2018. «Literatura misional y hagiografía en el siglo XIX: Jacinto Juanmartí, un misionero jesuita en Filipinas (1833-1897)». Hispania Sacra 70, 141: 321-338. https://doi.org/10.3989/hs.2018.024

$\begin{array}{ll}\text { Recibido/Received } & 12-02-2016 \\ \text { Aceptado/Accepted } & 17-02-2016\end{array}$

\section{INTRODUCCIÓN}

En marzo de 1900, en Manila, el misionero jesuita Guillermo Bennasar terminó de escribir unos «Apuntes biográficos sobre el P. Jacinto Juanmartí», uno de sus compañeros en Filipinas. Hacía tres años que su amigo

* Este trabajo se inserta dentro del proyecto de investigación Fronteras Culturales en el mundo hispánico (ss. XVI-XVII): entre ortodoxias y heterodoxias (HAR2014-52434-C5-1-P) del Ministerio de Ciencia e Innovación.

1 maria.aguilera@uab.cat / ORCID iD: http://orcid.org/0000-00019894-5923 había muerto en Tamontaca, la misión de Mindanao donde ambos habían trabajado juntos durante 15 años. Guillermo Bennasar Vadell nació en Santany (Mallorca) el 1 de septiembre de 1845. Entró en la Compañía de Jesús el 31 de mayo de 1879 y en 1881, al poco de terminar el noviciado, fue enviado a las misiones de Filipinas. Se inició en la isla de Joló, pero en 1882 ya fue destinado a Tamontaca, donde laboró hasta principios de 1899 , cuando fue evacuado a Manila por los disturbios tardíos derivados de la Revolución Filipina que se desencadenaron en la isla. Tras permanecer un año en el Ateneo Municipal se reincorporó con el resto de jesuitas a las misiones de Mindanao, concretamente a 
Zamboanga. ${ }^{2}$ Publicó catecismos, diccionarios bilingües y una gramática sobre la lengua nativa tiruray. ${ }^{3}$ Murió el 8 de julio de 1902 en altamar, cerca de Suez, cuando regresaba a España por enfermedad, contando 57 años de edad y 23 en la Compañía. ${ }^{4}$

El citado manuscrito sobre Jacinto Juanmartí se conserva en el Archivo Histórico de la Compañía de Jesús de Cataluña (Barcelona), antes llamado Archivo Histórico de la Provincia de Aragón (Sant Cugat). ${ }^{5}$ Bennasar no explica el material del que dispuso para la composición de esta obra, mezcla de literatura misional y hagiografía, pero deducimos que, aparte de sus propios recuerdos, pudo hacer uso tanto de los diarios e historias donde los jesuitas detallaban con esmero los acontecimientos y actividades más destacables de las residencias misionales, como sobre todo de las numerosas cartas que los misioneros escribían asiduamente a sus compañeros y en especial a su superior en Manila sobre sus inquietudes y su vida cotidiana en las misiones. Toda esta profusa documentación se conserva también en el AHSIC. En el caso del fondo epistolar, se demuestra una vez más la excepcional relevancia de esas cortas misivas que, además de divulgar noticias en el seno de la Orden, edificar, crear una identidad colectiva y suscitar el deseo de acudir a las misiones de ultramar ${ }^{6}$, podían servir de base fundamental para la redacción de obras como la que nos ocupa.

El autor tampoco menciona los motivos que le impulsaron a redactar el manuscrito, pero podemos suponer que se combinaron el deseo de Bennasar de revelar la naturaleza santa de su admirado compañero y el requerimiento de las instancias superiores de la Compañía de Jesús, siempre ávidas de ensalzar y difundir la valía y singularidad de sus miembros respecto a otras órdenes religiosas. Como veremos, el manuscrito se amolda perfectamente al discurso laudatorio jesuita, constituyendo un ejemplo más de obra destinada, no sólo a alimentar la vocación misional para atraer a nuevos afiliados, sino sobre todo a construir la identidad comunitaria de los jesuitas y a servir de instrumento político de consolidación de la posición de la Compañía de Jesús tanto en la colonia como en la metrópoli, en este caso tras su restauración a principios del siglo XIX.

La vocación misional universal de la Compañía de Jesús se puso de manifiesto tempranamente ya en sus Constituciones. Uno de los objetivos principales de la Orden, postulado por Ignacio de Loyola, era la salvación del prójimo, incluyendo la población «infiel», en la que tenían cabida los nativos de América y del resto de colonias del Imperio Hispánico. Esta meta expresaba la trascendencia de la caridad fraterna, la más importante y eficiente para el servicio de Dios, y además en grado universal. ${ }^{7}$ La introducción de los jesuitas en los territorito fronterizos de la monarquía hispánica desde el siglo XVI como elementos religiosos pero también

2 O’Neill y Domínguez 2001: vol. I, 408; 1880-1889 y 1899-1901. Catálogo de la Provincia de Aragón de la Compañía de Jesús (18641945): 89, 44, 48 y 49, respectivamente.

3 Bennasar 1888; ibídem 1892a; ibídem 1892b; ibídem 1892c; ibídem 1893; Tenorio (Sigayán) 1892.

4 «Catálogo de PP. y HH. jesuitas que han ido a Filipinas (18591919)». FIL 0066: 23. Archivo Histórico de la Compañía de Jesús de Cataluña (en adelante AHSIC).

5 Bennasar 1900. FIL 0185.1: 1-95. AHSIC.

Betrán Moya 2009: 173.

Ruiz Jurado 2005: 17-19. políticos fue seguida por la producción de una profusa literatura divulgativa que llamamos «misional», cuyo objeto no era servir sólo de elemento edificante dentro de la misma Orden, sino también como arma de crédito contra sus detractores, para lo que adoptaba un notable tono victimista. Con este género la Compañía divulgaba los éxitos evangélicos de la Orden dentro y fuera de ésta, fortaleciendo el espíritu corporativo a la vez que captaba la atención del lector europeo. La narración en primera persona aportaba mayor viveza y en ella se destacaba la heroicidad de sus protagonistas y el exotismo del lugar con el objetivo de encender nuevas vocaciones. Pese a su parcialidad, su tono complaciente y su carácter a veces ficticio, el valor histórico, religioso y también etnográfico, geográfico e incluso botánico y zoológico de la literatura misional es indiscutible. ${ }^{8}$

\section{INFANCIA Y PRIMEROS AÑOS}

Jacinto Juanmartí y Espot, hijo de Juan y Teresa, nació el 5 de febrero de 1833 en la aldea de Llarvent, vinculada a la parroquia de Montardit, del distrito municipal de Rialp, dentro del obispado de Urgel, provincia de Lérida. ${ }^{9}$ Según su hagiógrafo, ya desde su infancia vivió en un ambiente marcadamente piadoso que contribuyó decididamente a formar su futuro fervor religioso: «Hijo de padres labradores y cristianos a la antigua, recibió en sus primeros años aquella educación sólida y piadosa a la vez, que saben dar los padres verdaderamente cristianos y de costumbres patriarcales, patrimonio de otros tiempos, y que por desgracia tanto escasea en nuestros días». Para Bennasar, «había nacido para la piedad» y lo que más contribuyó a ello fue:

El vivir apartado desde sus primeros años de todo peligro del mundo, en el que tantos naufragan en los albores de la juventud, pues vivía en casa de un tío paterno, virtuosísimo y ejemplar sacerdote, quien no sólo se cuidó de formar su corazón, sino también de instruirle, primero en las materias de primera enseñanza y después en la latinidad.

El joven Jacinto, de carácter dócil, estudioso, inteligente y poseedor de una gran memoria, pronto hizo «concebir las más bellas esperanzas, que a la verdad no quedaron defraudadas». ${ }^{10}$ Bennasar destaca así la infancia y adolescencia piadosas, puras y prometedoras de Juanmartí, en la línea de las hagiografías modernas, pero sin narrar éxtasis, mortificaciones ni otros sucesos clave de éstas. ${ }^{11}$ Como veremos, nuestro hagiógrafo ahondó en las virtudes humanas y religiosas de su compañero, pero huyendo de la narración prodigiosa y extática.

Cuando Jacinto dominó suficientemente el latín su tío lo envió al Seminario de Urgel, donde cursó con éxito sus estudios hasta ordenarse como sacerdote el 13 de diciembre de 1857. Ya antes de esta fecha pidió ser admitido en la Compañía de Jesús, pero los superiores de la misma le aconsejaron esperar a ser ordenado. Así, en 1857 empezó el noviciado en Santa Coloma de Farners, pero poco después,

\footnotetext{
8 Pino Díaz 2005: 48-68; Betrán Moya 2009: 172-175.

9 Pastells 1916-1917: vol. III, 232.

10 Bennasar 1900: 1

11 Betrán Moya 2009: 176.
} 
como consecuencia de unas fiebres que le debilitaron en gran medida, fue enviado a Loyola, «donde se distinguió por su observancia y aprovechamiento en la virtud». Después de realizar los votos del bienio (1859), fue operario en Balaguer (1859-1861) y pronto fue enviado al Colegio Máximo de San Marcos de León a profundizar sus estudios en Teología (1861-1863). Hizo su tercera probación en Manresa. ${ }^{12}$ Sus superiores detectaron muy pronto su don para el gobierno y por ello le nombraron, recién hechos sus votos, ministro de los teólogos en San Marcos de León. Incluso pensaron en enviarlo como superior a las misiones de Sudamérica. ${ }^{13} \mathrm{Sin}$ embargo, la eterna escasez de misioneros en Filipinas hizo que finalmente decidieran destinarlo a ese archipiélago. ${ }^{14}$

La época en la que Juanmartí realizó sus estudios y entró en la Compañía coincidió, por un lado, con el florecimiento de una nueva etapa misional en el mundo y, por otro, con el momento en el que el proceso de restauración de la Compañía de Jesús en España y sus territorios de Ultramar llegaba a su culminación. Después de la decadencia sufrida en la época de la llustración, cuyas tesis eran contrarias a la evangelización de la población «infiel», el apostolado misionero vivió una revitalización durante el siglo XIX que se ha denominado la "segunda primavera de las misiones». Las nuevas conquistas coloniales de Europa, unidas a los principios de igualdad entre hombres y razas de la Revolución Francesa y a la reafirmación de la fe que se siguió de ésta, fomentaron la creencia de que era necesario expandir el mensaje evangélico a toda la humanidad e impulsaron la expansión misionera. ${ }^{15}$ Por su parte, los intelectuales románticos, fascinados por la literatura misional, cargaron contra la literatura ilustrada que vilipendiaba la Iglesia y toda la tradición cristiana. Así, el Romanticismo literario difundió una nueva imagen del mundo misional, donde la misión se erigía como paradigma de la caridad y de la virtud cristiana, pero también como instrumento de la Iglesia para fomentar no sólo el bien espiritual individual sino también el desarrollo y civilización de los pueblos. El objetivo misional ya no era sólo evangélico, sino también humano. Esta mentalidad romántica aparece en numerosas obras, pero sin duda la más afamada fue El Genio del cristianismo de René Chateaubriand de 1802, que influyó de forma notoria en toda la literatura misional del siglo XIX y en adelante. Esta fiebre misional promovió asimismo la reimpresión de las crónicas jesuitas de los siglos XVII y XVIII y también la publicación de revistas misionales y de obras de difusión popular que proclamaban los trabajos y triunfos de los misioneros y que excitaron el interés y la preocupación del pueblo por la expansión de la doctrina cristiana en aquellas tierras lejanas. La fiebre misionera fue tal que nacieron nuevas congregaciones religiosas encauzadas exclusivamente al apostolado misionero, y no fueron tan sólo de género masculino, sino que las mujeres también salieron de los conventos de clausura para entregarse a la evangelización e instrucción de la humanidad. La primera de estas congregaciones misioneras fue la Sociedad de Sagrados Corazones, que nació en 1805 y fue seguida por muchas otras. En definitiva, este contexto histórico colonial

\footnotetext{
12 Bennasar 1900: 2-3; O’Neill y Domínguez 2001: vol. 1, 2160.

13 Bennasar 1900: 76.

14 Ibídem: 3.

15 Puech 1981: vol. 8, 88.
}

y restauracionista, unido a la avalancha propagandística, suscitó la aparición de un "romanticismo misionero» que logró proporcionar a la Iglesia tanto una hueste de adeptos dispuestos a morir allá donde les enviasen como una suma considerable de recursos para llevar a cabo el proyecto de expansión evangelizadora. ${ }^{16}$

Sin embargo, respecto a este fenómeno España no puede compararse con otros países, como Italia y sobre todo Francia, que fue en este período el Estado más emprendedor y con mayor despliegue en el ámbito misionero. Pero, pese a lo convulso de la política interna española del siglo XIX, sí hubo muchas misiones propias en el extranjero. El principal espacio exterior de labor misionera para los religiosos españoles siguió siendo América. La independencia de la América hispana interrumpió temporalmente el envío de misioneros, aunque los que ya residían allí continuaron con su labor. Sin embargo, la posterior expulsión de las órdenes religiosas de España hizo que muchos de ellos emigraran a América. Asimismo, su progresivo restablecimiento posterior en España conllevó de nuevo su envío al territorio americano. Por otra parte, Cuba, Puerto Rico y Filipinas siguieron siendo atendidas por religiosos españoles durante el resto de su etapa hispánica. De hecho, esta fue la razón por la que los gobiernos liberales y antireligiosos que hubo en España ese siglo permitieran que continuaran abiertos los colegios de formación de misioneros para las colonias de ultramar, e incluso que se fundaran otros. ${ }^{17}$

El restablecimiento de la Compañía de Jesús por parte de Pío VII en 1814 implicó la restauración de su estatus y privilegios, así como un implícito rechazo a las ideas ilustradas y jansenistas que tanto habían criticado a los jesuitas. Pero sobre todo, el gesto del papa era un reconocimiento a su capacidad de movilización y a su pasada labor, celo y entrega en el ámbito evangelizador, en aras de incluir a la Compañía en la nueva etapa misional y asegurar el éxito del proyecto. ${ }^{18}$ En España la Compañía quedó restaurada en 1815 y, tras las vicisitudes de la primera mitad de siglo derivadas del liberalismo español, Isabel II emitió la Real Cédula de 19 de octubre de 1852 en la que no sólo autorizaba el regreso de los jesuitas a Filipinas sino que además les encargaba la reducción y catequismo de los naturales de las islas de Mindanao y Joló. ${ }^{19}$ Este territorio, más alejado de Manila, más plural étnica, cultural y lingüísticamente y más convulso, no sólo estaba menos pacificado, evangelizado e hispanizado que el resto del archipiélago ${ }^{20}$, sino también menos avanzado en cuanto a infraestructuras básicas y vías de comunicación. ${ }^{21}$ La Misión Filipina fue gobernada desde la sede de Manila y estuvo compuesta por un padre superior, un procurador, un secretario y un coadjutor. En Mindanao, los padres superiores de Surigao y Zamboanga fueron a su vez vicesuperiores del de Manila en sus respectivas

16 López 2004: 103-105; Duré y Laboa 1998: 262.

17 Jiménez Duque 1974: 104-105.

18 López 2004: 111-114.

19 Sobre el regreso de los jesuitas a Mindanao y el estado de sus misiones, «Relación histórica y estado de las Misiones de la Compañía de Jesús en Filipinas». FIL 0010. AHSIC; Fernández Cuevas 1860: vol. 8, 5-61; Saderra Masó 1924; Cava Mesa 2001: 619-640.

20 Sobre el estado de Mindanao a finales del siglo XIX, ver: González Parrado 1893; Ricart 1883: vol. 10, 587-610; Pastells 1888: 478-491; ibídem 1892: vol. 9, 599-667.

21 Sánchez Gómez 1989: 82-116; Piqueras Villaldea 2002. 
regiones. Inicialmente la Misión Filipina perteneció a la única y exclusiva provincia jesuítica que existía en España, pero en 1863 ésta se dividió en dos: la provincia de Castilla y la provincia de Aragón. Ésta última sería la que quedaría vinculada a la Misión de Filipinas, confirmándose el número mayoritario de jesuitas aragoneses, valencianos, catalanes y mallorquines. El considerable esfuerzo misional que requirió siempre Mindanao se tradujo en una escasez constante de jesuitas a lo largo del siglo XIX, ya que la provincia de Aragón no siempre pudo proporcionar un número elevado y regular de padres y hermanos, y algunas veces hubo que solicitar religiosos al resto de provincias de la Compañía. ${ }^{22}$

No debemos olvidar, sin embargo, que en las últimas décadas del siglo XIX en Filipinas se agravó la fractura entre el poder civil y el religioso, iniciada ya a finales del siglo XVIII, y se cuestionó seriamente el poder y omnipresencia de las órdenes religiosas. Éstas, artífices de la conquista, eran un pilar vital para el sostenimiento del régimen colonial español en las islas, pues constituían prácticamente los únicos habitantes españoles de gran parte del archipiélago y también los únicos conocedores de las numerosas lenguas nativas. En el siglo XIX jesuitas, agustinos, franciscanos, recoletos, dominicos y otras órdenes prosiguieron o reiniciaron sus labores evangélicas y también su destacado papel en la administración colonial. Pero las autoridades políticas deseaban controlar más directamente las islas. Se habían agudizado las tensiones entre el clero regular y el secular y, además, había aumentado el resentimiento del clero nativo, apartado de las parroquias por el clero regular español, elemento que sería clave para el estallido de la futura Revolución Filipina en 1896. El creciente anticlericalismo, por su injerencia política ajena a su labor espiritual, unido al renovado interés internacional por Asia y el Pacífico y a la crisis en Cuba, hizo que el gobierno español reforzara las atribuciones de las autoridades coloniales en el archipiélago, aumentara el control sobre la población, se acercara a las élites autóctonas y reformara el gobierno local. Estas modificaciones, a menudo contradictorias, desencadenarían tensiones entre la administración local y las órdenes religiosas, reticentes a perder su posición privilegiada. ${ }^{23}$

Primeros años en Filipinas: de loS colegios de MaNila a LAS MISIONES DE MINDANAO (1865-1874)

En 1864, cuanto contaba 31 años, Jacinto Juanmartí formó parte de la cuarta expedición destinada a Manila desde la restauración de la Compañía en Filipinas. La primera había partido en 1859, casi un siglo después de la expulsión de los jesuitas de todos los territorios de la monarquía hispánica. El jesuita partió de Barcelona el 5 de julio de 1864 en la fragata «Reina de los Ángeles», que pasó por Cádiz el 20 de julio y a continuación emprendió el viaje transoceánico hacia el oeste. Lo acompañaban los padres Francisco X. Baranera, Domingo Bové, Pedro Llausás y Baudilio Soler, los hermanos estudiantes Juan Ricart y Jaime

22 Cava Mesa 2001: 623-625.

23 Sobre esta controversia, ver: Elizalde Pérez-Grueso 2015a: 151176; ibídem 2015b: 185-222; Inarejos Muñoz 2011: 741-762; ibídem 2013: 23-40.
Nonell, y los hermanos coadjutores Francisco Viñolas, Jaime Torrents y Segismundo Berengueras. Francisco X. Baranera viajaba en calidad de padre superior y Jacinto Juanmartí de padre espiritual. Justamente sería en la siguiente expedición, la quinta, que partiría el 15 de octubre de 1865, cuando esos viajes empezaron a efectuarse "vía Suez», partiendo del puerto de Barcelona sin desviarse hacia Cádiz y llegando a Manila mucho antes. ${ }^{24}$ La travesía de Juanmartí fue, pues, larga, fatigosa e incómoda. Llegaron a Manila el 11 de enero de 1865 , tras cinco meses y 23 días de viaje. ${ }^{25}$

El 23 de enero de 1865, pocos días después de la llegada de Juanmartí a la capital, se inauguraba la Escuela Normal de Maestros de Manila, el segundo centro educativo confiado a los jesuitas desde su llegada a las islas, cuyo objetivo era formar maestros que impartieran la instrucción primaria y el castellano en las escuelas de Filipinas. Sólo diez años después, el número de alumnos ascendía a 600 . No hubo ningún otro centro de este tipo hasta la etapa norteamericana de Filipinas. ${ }^{26}$ Previamente, por decreto del 1 de octubre de 1859, el gobernador general había ordenado que la única escuela primaria de Manila, Ilamada Escuela Pía, pasara a ser dirigida por los jesuitas. El centro funcionó tan eficazmente que en 1865 el ayuntamiento de la ciudad solicitó al gobierno español que los estudios abarcaran también la enseñanza secundaria, cosa que fue aprobada. De esta manera, dicha escuela se convirtió en el célebre Ateneo Municipal. ${ }^{27}$ A Jacinto Juanmartí se le adjudicó, a su llegada, el cargo de prefecto de estudios y de espíritu en la Escuela Normal de Maestros, que desempeñó durante unos pocos meses de 1865. Sin embargo, sus dotes de mando hicieron que el 24 de diciembre del mismo año se le nombrara vicerrector del Ateneo. ${ }^{28}$

Sólo dos años después, a finales de 1867, Jacinto Juanmartí fue destinado a la isla de Mindanao, concretamente a la misión de Zamboanga, donde se inició como misionero. ${ }^{29}$ El 8 de septiembre de 1871 fue nombrado superior de esa misma residencia pero, curiosamente, el 1 de noviembre volvió a ocupar el cargo el anterior superior, Juan Vidal ${ }^{30}$, pues Juanmartí se había trasladado a finales de octubre a Dumalong (futura Ayala), una reducción de la residencia, en compañía del hermano Figuerola. Ese inusual y fugaz paso por el puesto de superior residencial no se debió a una rectificación espontanea de sus superiores, pero tampoco a una queja ni a una falta de obediencia por parte del implicado. La cuestión era que Jacinto se sentía inquieto por los numerosos cristianos viejos zamboangueños que

24 «Catálogo de PP. y HH. jesuitas que han ido a Filipinas (18591919)»: 6. El Canal de Suez no fue inaugurado hasta 1869, así que tanto la quinta misión como las inmediatamente posteriores no pudieron navegar por él. Dado que la brevedad de esos viajes indica que, indudablemente, no rodearon África ni Sudamérica, se deduce que los misioneros debieron utilizar el servicio ferroviario Alejandría-Mar Rojo habilitado desde 1850 .

25 Bennasar 1900: 3.

26 Arcilla 1988: 16-35; Borges Morán 1992: vol. II, 740-741.

27 Pastells 1916-1917: vol. I, 12-21.

28 Bennasar 1900: 4; 1865. Catálogo de la Provincia de Aragón de la Compañía de Jesús (1864-1945): 34.

29 Bennasar 1900: 7-9. Sobre la labor de Juanmartí en Zamboanga, ver también: Pastells 1916-1917: 73-74 y 76.

30 1872-1873. Catálogo de la Provincia de Aragón de la Compañía de Jesús (1864-1945): 34 y 33, respectivamente. 
residían en la apartada Dumalong, lejos de la influencia de los jesuitas y de las autoridades. Esa preocupación le decidió a abandonar el cargo de superior para poder atender personalmente ese problema. Así, aprovechando la visita a Zamboanga del padre visitador José Lluch, le pidió permiso para tal fin y emprendió su proyecto. Lo verdaderamente destacable de su labor en Dumalong, sin embargo, fue su acercamiento a los hostiles subanos, una etnia sin cristianizar que moraba los montes cercanos, pues fue el primer jesuita de la Compañía restaurada que se ocupó de ellos. Varios de sus futuros compañeros de fatigas le oyeron muchas veces referirse con cariño a aquella época en que vivió inmerso entre los subanos. Fue durante su estancia en Dumalong cuando llegó el momento de hacer sus últimos votos, el 19 de marzo de 1873, junto a los padres Francisco Ceballos y José Casadevall y el hermano Venancio Segarra. ${ }^{31}$

\section{TAMONTACA: LA MISIÓN DE SU VIDA}

En 1874, a los 41 años, Jacinto fue destinado al distrito de Cotabato como padre superior de la residencia homónima, que comprendía tres casas-misión: Tamontaca (la cabecera), Cotabato y Polloc. $^{32}$ La residencia de Cotabato era especialmente complicada por estar situada en el corazón del territorio moro. Desde los inicios de la conquista los moros habían sido el grupo más resistente a la evangelización y también el más conflictivo. Además, era una zona sin población cristiana, ni vieja ni nueva. Paradójicamente, había sido en este distrito donde los jesuitas habían empezado sus misiones en la isla sólo 13 años antes. El jesuita José Fernández Cuevas, tras explorar en 1860 las costas norte y sur de Mindanao ${ }^{33}$, había resuelto de acuerdo con el obispo de Cebú que las misiones debían iniciarse en alguno de los distritos del norte, menos convulsos, mejor comunicados y con una base poblacional cristiana, para luego introducirse progresivamente en el territorio pagano. Pero el gobierno español quiso que los misioneros empezaran por el sur y se introdujesen en el distrito de Cotabato a la vez que lo hacían sus tropas, que debían tomar posesión del territorio estableciéndose en el Río Grande o Pulangui. ${ }^{34}$ El gobierno español había intentado destruir en varias ocasiones el poder y la piratería de los moros del Río Grande, llamados moros maguindanaos por ocupar la sultanía de Maguindanao. En 1596 Esteban Rodríguez de Figueroa fue el primero en intentarlo, pero murió en la aventura, que fue un fracaso. ${ }^{35}$ En 1637 el gobernador Sebastián Hurtado de Concuera realizó otra tentativa con mayor éxito, pero no se consolidó el triunfo en la zona. ${ }^{36}$ Fue a mitad del siglo XIX cuando el gobierno español resolvió de una vez por todas dominar Mindanao y muy especialmente el Río Grande. En 1852 se estableció una base naval en Polloc, que hacía de punto

31 Bennasar 1900: 11-15; Pastells 1916-1917: 76-80; O’Neill y Domínguez 2001: vol. III, 2160.

32 1875. Catálogo de la Provincia de Aragón de la Compañía de Jesús (1864-1945): 33; O’Neill y Domínguez 2001: vol. III: 2160.

33 Fernández Cuevas 1860: 5-61.

34 «Historia de la Misión de Río Grande de Mindanao (Tamontaca)». 1871-1879. FIL 0145: 1-2. AHSIC.

35 De Morga 1890: 26-53; De la Costa 1967: 279-301; Montero y Vidal 1888: vol. I, 136-147.

36 De la Costa 1967: 377-403; Montero y Vidal 1888: vol. I, 165-174. intermedio entre las bases de Zamboanga y Davao. El Real Decreto de 31 de julio de 1860 dispuso la creación de un gobierno general político-militar en Mindanao y la división administrativa de la isla en seis distritos. El mismo año se sometió el sultán de Maguindanao al gobierno insular, y su pueblo, Cotabato, fue ocupado por tropas del gobierno. ${ }^{37}$ En este contexto, el 23 de agosto de 1861 partió de Manila la primera misión de la Compañía restaurada a Mindanao, con los padres Juan Bautista Vidal y José Ignacio Guerrico y los hermanos Venancio Belzunce y José María Zumeta, que desembarcó en Polloc el 16 de septiembre junto con las tropas y sus mandos, entre ellos el primer comandante general de Mindanao, José García Ruiz. Fue precisamente Tamontaca el lugar elegido para empezar la labor en la isla, porque las tropas destinadas a dominar los dos brazos del Río Grande podrían apoyarles y protegerles. Pero hacía más de un siglo que los españoles habían sido expulsados de Tamontaca y del Río Grande por los moros, así que no había ni una sola casa. Tanto las tropas como los jesuitas tuvieron que alojarse en tiendas de campaña de lona. Así pues, a la llegada de Jacinto Juanmartí al distrito de Cotabato hacía poco más de una década que los jesuitas y el ejército español se habían establecido en la zona más espinosa de la isla, donde además no quedaba casi ni una sombra de la labor de los antiguos jesuitas. ${ }^{38}$ En esa época laboraban allí los padres Ramón Beá (el anterior superior), Luis Tello y Domingo Viñals, y los hermanos coadjutores Francisco Viñolas, Francisco Palou y José Zumeta. ${ }^{39}$

Cotabato no era entonces una reducción, sino un campamento militar, donde había algunos deportados. No había iglesia ni convento, la base de cualquier misión, sino solamente un pequeño camarín, que hacía a su vez de capilla. Inmediatamente, Jacinto dispuso la construcción de un convento y una iglesia decentes ${ }^{40}$, "pues su actividad, que corría pareja con su celo, no le consentía dilatar un solo momento obra de tanta necesidad $»{ }^{41}$

Por su parte, Tamontaca fue una misión singular. Los jesuitas no sólo construyeron un convento y una iglesia ni se limitaron a crear un pueblo con los tirurayes que vivían en los montes cercanos. Varios historiadores han realizado estudios sobre su funcionamiento y excepcionalidad dentro del panorama misional. ${ }^{42}$ En primer lugar, Tamontaca poseía los Establecimientos de libertos, es decir, dos casas-colegio donde residían y se instruían niños y niñas. La fundación de estos centros ya fue sugerida por José Fernández Cuevas tras su viaje de exploración de la isla. ${ }^{43}$ Los jesuitas que llegaron al distrito en 1861 también acariciaron esta idea, pero los Establecimientos no nacieron hasta 1872 , dos años antes

37 Arcilla 1978: 16-17. Sobre la ofensiva de mediados del XIX, ver: Montero y Vidal 1888: vol. II, 486-491; Togores Sánchez 2001: 675-698.

38 «Historia de la Misión de Río Grande de Mindanao (Tamontaca)»: 2-3 y 5-8; Nieto Aguilar 1894: 38; "José Ignacio Guerrico a PS. Juan B. Heras, Tamontaca 5 enero 1880», en 1880. Cartas de los PP. de la Compañía de Jesús de la Misión de Filipinas, 1879-1880: vol. 3, 164-165. Para una narración más exhaustiva, ver: Pastells 1916-1917: 28-32.

39 1874. Catálogo de la Provincia de Aragón de la Compañía de Jesús (1864-1945): 34-35.

40 Bennasar 1900: 11 y 16.

41 Ibídem: 18.

42 Bernard 2002a: vol. 5: 215-239; Madigan y Cushner 1958: 322336; ibídem 1961: 81-94; Cushner 1963: 223-232.

43 Fernández Cuevas 1860: 35-36. 
de la llegada de Juanmartí. Ese año, como consecuencia de una grave hambruna, los moros vendían en el Río Grande niños esclavos a bajo precio, coyuntura que aprovechó el comandante general de Mindanao, Luis Fernández-Golfin, para proponer al gobierno de Manila la idea de comprar a esos niños. La propuesta fue aceptada y Fernández-Golfin rescató a un grupo de niños y otro de niñas que fueron puestos, respectivamente, bajo el cuidado de los jesuitas y de unas Madres procedentes del Beaterio de la Compañía de Jesús de Manila. ${ }^{44}$ La creación de este orfanato respondía a un objetivo dual. Por un lado, este tipo de centro caritativo fundado en un entorno hostil se enmarcaba en la nueva ola misional del siglo XIX donde la actividad civilizadora y humanitaria se añadía a la evangélica con igualdad de relevancia. Por otro lado, mediante esos pequeños de ambos sexos se pretendía crear una sociedad instruida y sólidamente cristiana. ${ }^{45}$ Ya los primeros misioneros jesuitas que laboraron en las islas habían comprendido que los niños eran el sustrato más moldeable $y$, por lo tanto, los mejores sujetos donde sembrar la doctrina cristiana para lograr su posterior implantación en el resto de la población. ${ }^{46}$

En segundo lugar, Tamontaca era una colonia agrícola. Estaba muy bien situada, en un terreno apropiado y cerca del río. Jacinto procuró siempre cultivar palay (arroz con cáscara) a gran escala para tener cubiertas las necesidades de sus habitantes, pues era el cultivo más extenso y vital en Filipinas, pero también amplió los cultivos plantando caña de azúcar, café, cacao, maíz, coco y árboles frutales, todo ello tanto para proveer a los Establecimientos como para vender el excedente en beneficio de los mismos. Además, Jacinto fue adquiriendo carabaos y procuró su cría, pues estos animales eran necesarios tanto para trabajar los cultivos como para la vida en Filipinas. Se esforzó también en tener un rebaño de vacas que llegó a ser de más de cuatrocientas cabezas, pues era barato, de fácil cuidado y muy útil para proveer de carne a los Establecimientos. ${ }^{47}$

Todo el afán de Jacinto era producir más y más recursos para poder rescatar más niños de la esclavitud. De ese modo, luego se podrían trasladar algunos para que sirviesen de base poblacional inicial para formar otros núcleos. ${ }^{48}$ Aparte de las casas-colegio, Tamontaca también comprendía una serie de casas donde residían aquellos nativos adultos predispuestos a radicarse allí y evangelizarse. Uno de los mayores tormentos de Jacinto era no poder liberar y acoger a todos aquellos indígenas esclavos, niños y adultos, que así lo pedían:

44 El Beaterio de la Compañía de Jesús, primera congregación religiosa en Filipinas, fue fundado en 1684 en Manila por la mestiza china Ignacia del Espíritu Santo, gracias al apoyo del jesuita Paul Klein. Fundó el Colegio del Beaterio de San Ignacio, cuya labor educativa abarcaba tanto a niñas españolas como a mestizas y nativas. Borges Morán 1992: 713 y 741. Sobre esta célebre beata, ver: Schumacher 2002: 416-434.

45 Bennasar 1900: 16-17; Pastells 1916-1917: 132-136; «Origen y progresos del Orfanotrofio de Tamontaca y Registro de libertos ingresados de uno y otro sexo que en él ingresaron desde el 9 de septiembre de 1872 hasta el 10 de octubre de 1893». FIL 0147: 2-3. AHSIC. Para una breve síntesis de la fundación, organización y detalles del orfanato, ver: Guerrico 1881.

46 Gutiérrez 1992: 117.

47 Bennasar 1900: 27-29; Bernard 2002: 228

48 «Jacinto Juanmartí a PS. Juan Ricart, Tamontaca, 25 Enero 1881», en 1881. Cartas de los PP. de la Compañía de Jesús de la Misión de Filipinas, 1880-1881: vol. 4, 138.
De algún tiempo á esta parte van presentándose varios sujetos moros que piden por caridad que se les rescate de la esclavitud de alma y cuerpo en que están, con razones á veces tan poderosas, que parten el corazón de pena. Además de las cuatro familias moras, que se acogieron aquí estos meses pasados, y de otros cuatro ó cinco niños y niñas que han venido posteriormente, todos los cuales han sido rescatados, ha habido otros que los hemos despedido por no tener recursos para ello. Uno fué un pobre moro de aquí cerca, y fué tal su desgracia, que el dato se apoderó de su mujer y de sus hijos, y los hizo esclavos. Conociendo lo bien que les iría, si del dato moro pudieran pasar sus dos ó tres hijos á este establecimiento de libertos, acudió aquí por una, dos, tres y más veces, ofreciéndose á lo que quisiésemos, con tal que recogiésemos á sus hijos; mas todo fué en vano, porque no teníamos recursos para rescatarlos. Ahora mismo me están instando para que rescate á tres hermanos, dos hombres y una muchacha, que les han hecho esclavos por deuda de sus padres de 50 pesos. Son hermanos de otro que tenemos aquí bautizado de pocos días, y serán los primeros rescatados con la limosna que me envía. ${ }^{49}$

La instrucción de los niños abarcaba tres ámbitos: el religioso, el profesional y el referente a la alfabetización. En palabras de Jacinto, "en el establecimiento se les enseña a rezar desde pequeños, y aprenden prácticamente la doctrina cristiana, se acostumbran a obedecer, a trabajar y a vivir honestamente». El primer ámbito, el religioso, era el más valorado. Se enseñaba a los niños la doctrina cristiana y se les hacía asistir a misa y practicar la oración a diario. Se les administraba progresivamente los sacramentos, desde el bautismo inicial hasta el matrimonio y la extremaunción. Sólo la confirmación les estaba vedada, dado que no había obispos en Mindanao en aquella época. ${ }^{50}$ Jacinto Juanmartí comentaba sobre la instrucción religiosa:

En la iglesia, donde se reúnen niños y niñas, rezan y cantan, formando un tan bueno y nutrido coro, que le enternece á uno y le mueve á alabar á Dios, nuestro Señor, que sabe sacar sus alabanzas de la boca de niños y niñas, antes esclavos del demonio y ahora hijos suyos, y que ha convertido esta comarca antes guarida de piratas y centro del islamismo, en templo de su gloria, donde es bendecido y adorado.

En segundo lugar, los niños aprendían un oficio útil dentro de la colonia, ya fuera el de carpintero, herrero, albañil o agricultor, siempre en base a sus habilidades: «Si viera V. $R$. cómo saltan y brincan en los recreos, cómo trabajan, aun los pequeñitos, en pilar arroz, sembrar y cortar palay y en las demás faenas del campo, según la capacidad de cada uno». Por su parte, las niñas aprendían tareas del hogar, pero también algunas labores del campo. Su trabajo y el de sus maestras era el que más elogios merecía del misionero:

En el establecimiento de las niñas no sé qué admirar más, si la abnegación, caridad y paciencia de las Religiosas que las dirigen, que llevadas sólo del amor de

49 «Jacinto Juanmartí a José Ignacio Guerrico, Tamontaca, 18 diciembre 1880 », en 1881. Cartas de los PP. de la Compañía de Jesús de la Misión de Filipinas, 1880-1881: vol. 4, 133-134.

50 Mindanao estuvo bajo el obispado de Cebú hasta 1865, cuando se creó la diócesis de Jaro (con sede en la isla de Panay), que pasó a custodiar la zona sudoeste de la isla, incluyendo Tamontaca. Hasta 1910 Mindanao no tuvo su propia diócesis, con sede en Zamboanga. 
Dios y del bien de estas criaturas, han venido á estas tierras sin recompensa alguna, y careciendo á veces hasta de lo necesario para la subsistencia, ó bien la admirable trasformación de las niñas que toman á su cargo. Pues vienen éstas de los moros las más medio desnudas, toscas, ignorantes y llenas de malos resabios, si son crecidas; y si pequeñas sucias y asquerosas muchas de ellas, más á los pocos días, ya quedan otras y se ponen desconocidas, y no tardan en dejarse entender y en aprender las oraciones del cristiano; pues no le falta capacidad y disposición á esta raza mora, para acomodarse á la vida social y cristiana; y hasta se ve en ellos más energía y capacidad que en las demás razas indígenas. Da gusto la claridad y despejo con que responden á la doctrina cristiana, que se les pregunta todos los domingos en la iglesia. Ellas cosen, lavan, planchan, leen y escriben. Trabajan mucho en la sementera para el plantío y corte del palay, al sol, á la lluvia y en el barro, siempre acompañadas por una de las Madres, que les sirve de ángel custodio; y en medio de estas faenas se oyen resonar los cánticos religiosos que han aprendido, con muy afinadas y armoniosas voces, que muestran la alegría y contento que experimentan en la vida nueva de cristianas.

Por último, se enseñaba a ambos sexos a leer y escribir. Sin embargo, se podría añadir otro ámbito de aprendizaje: el de vivir en esa comunidad de granjeros independientes. Cuando los niños crecían, se casaban y recibían un pedazo de tierra, un carabao, utensilios y suficiente comida como para mantenerse hasta la obtención de su propia cosecha, pero sobre todo seguían bajo la «vigilancia paternal» de los jesuitas para «dirigirlos y hacer que prosigan por el buen camino»:

[...] no se les deja abandonados á sí mismos y á sus malos instintos, porque pronto perderían, lo que con mucho tiempo han ganado en costumbres y en laboriosidad, y se entregarían, como los demás moros de su raza que nos rodean, á la holgazanería y á la pasión diabólica del juego, que no les deja hacer cosa buena y les conduce á todos los vicios. De aquí los robos, las riñas y las muertes tan frecuentes entre ellos. ${ }^{51}$

Se aprecia en esta serie de descripciones que Juanmartí, como los misioneros de los siglos anteriores, percibía la cultura y costumbres indígenas como incivilizadas y veía a los nativos desde una óptica paternalista. Bennasar nos aporta un fragmento muy claro al respecto: “'iPobrecitos!' Decía a veces, 'no son para más'. Como aquel padre cariñoso que procura disimular y aun disculpar las faltas de sus hijos díscolos. Aprendamos, pues, del Padre Juanmartí, a amar a nuestros súbditos, desagradecidos, como un padre bueno ama a un hijo malo». ${ }^{52}$ Los religiosos habían querido demostrar siempre la necesidad e incluso la obligación moral de los europeos de convertir a esos salvajes y de tutelarlos. ${ }^{53}$ Así, Jacinto describía un panorama desolador para luego ensalzar la efectividad de las conversiones que ellos mismos, con tanto esfuerzo, lograban.

En definitiva, Jacinto Juanmartí reglamentó la vida religiosa pero también la laboral en la misión. Creía que valía la pena invertir tiempo, paciencia y recursos en Tamontaca

51 «Jacinto Juanmartí a PS. Juan Ricart, Tamontaca, 25 enero 1881», en 1881. Cartas de los PP. de la Compañía de Jesús de la Misión de Filipinas, 1880-1881: vol. 4, 138-140; Bernard 2002: 226-228.

52 Bennasar 1900: 87.

53 Betrán Moya 2009: 178-179 y 181-182. porque esa nueva comunidad cristiana, sedentaria, compacta y autosuficiente erigida en el corazón del territorio musulmán podía convertirse en el núcleo de atracción de la población mora de la región. En aquella época, como en los siglos anteriores, intentar catequizarlos y bautizarlos siguiendo el mismo método que con el resto de nativos se consideraba una pérdida de tiempo. ${ }^{54}$ Se ha llegado a comparar Tamontaca con las reducciones jesuíticas del Paraguay, pese a distar un siglo de ellas, por ser ambos tipos de establecimientos una especie de experimento sociológico que trataba de erigir una isla cristiana en un entorno pagano y hostil. Sin embargo, existe una diferencia sustancial. En las reducciones paraguayas toda la tierra estaba en manos de un solo propietario, que conformaba la única «comunidad». Incluso en las haciendas filipinas una familia o una corporación eran las únicas propietarias. En cambio, en Tamontaca existía una comunidad formada por granjeros independientes cuyos esfuerzos estaban destinados, no sólo a mantenerse a ellos mismos, sino también a sustentar el orfanato y a sufragar el resto de trabajos de la misión. ${ }^{55}$ La misión de Tamontaca no se erigió sólo para evangelizar a los nativos y salvar sus almas, o para introducirlos en la vida social a imagen de los europeos, sino también para socorrerles en el aspecto más terrenal y enseñarles a producir su propio sustento para así convertirles en cristianos "civilizados» y autosuficientes. Existe un salto cualitativo entre las misiones de los antiguos jesuitas, mayormente dirigidas al cuidado espiritual de los nativos, y las nuevas misiones del siglo XIX en Filipinas, cuyo fin era salvar al ser humano tanto en el cielo como en la tierra.

\section{EL HOMBRE FRENTE AL RELIGIOSO: DE LA SALVACIÓN DE LAS ALMAS A LA FIEBRE HUMANITARIA}

En palabras de Bennasar, «El Padre Juanmartí era de un corazón muy grande, y sus deseos de ver entendida la luz del Evangelio casi no tenía límites». ${ }^{56}$ Jacinto se esmeró siempre mucho en dar gran esplendor al culto religioso. ${ }^{57}$ Le agradaba tener una iglesia decente y bien ornamentada donde poder realizar buenas y vistosas funciones. Para comunicar su devoción por el Sagrado Corazón de Jesús estableció el Apostolado, nombrando celadores y celadoras para que cada uno se encargara de sus respectivos coros. También le complacía que la concurrencia fuera numerosa. Cada primer domingo de mes había exposición mañana y tarde. Durante el año se hacían varias novenas, pero la del Sagrado Corazón y la de la Inmaculada, patrona de aquella iglesia, se hacían con mayor solemnidad. ${ }^{58}$ Todos los niños del orfanato confesaban y comulgaban cada tres meses. Jacinto se preocupaba de su instrucción y de su formación moral y humana, y hacía uso de innumerables métodos para estimular su fervor religioso. Cada año se realizaban ejercicios espirituales para los niños y para la gente del pueblo y Juanmartí rogaba mil veces por su asistencia al acto, sin cansarse jamás aunque viera sus expectativas defraudadas. ${ }^{59}$ Como la mayoría de misioneros de Filipinas,

\footnotetext{
54 Bennasar 1900: 22-24.

55 Cushner 1963: 232; Bernard 2002: 228.

56 Bennasar 1900: 62.

57 Ibídem: 11.

58 Ibídem: 52.

59 Ibídem: 92-93.
} 
Juanmartí era un jesuita volcado en su labor evangelizadora y siempre preso de un profundo sentimiento de frustración fruto de la imposibilidad de atender a la inmensa cantidad de nativos todavía sin cristianizar:

No sé, Padre mío, decir lo que siente uno al verse en estos sitios, rodeado por todos lados de monteses, sentados en las tinieblas de la infidelidad y en las sombras de la muerte [...]. Y cuando considero que la Compañía los tomó a su cargo al venir a Mindanao, y los ves como pajaritos en el nido, que al acercarse sus madres abren sus bocas para que les den de comer, y como niños que van detrás de sus madres pidiéndoles pan, no puede menos de dolerme en el alma al pasar por sus tierras oírles pedir con toda razón y no poderles dar el pan de la celestial doctrina. Hora es ya de que amanezca para ellos la luz de la verdadera fe. ${ }^{60}$

La obsesión por la salvación del máximo número de almas seguía muy presente en el corazón de los jesuitas, como también la visión del demonio como figura omnipresente en las Indias y culpable absoluto del paganismo indígena. ${ }^{61}$ A finales de 1882 una epidemia de cólera asoló todo el distrito, desbordando a los jesuitas. Al respeto, Juanmartí comentaba, abrumado:

Al contemplar tanta mortandad en esta gran cuenca, cuan bien vendría que hubiese alguno de nosotros dispuesto y desocupado de otras atenciones imprescindibles, que pudiese recorrer las rancherías de moros y demás infieles para sacar algunas almas de las garras del demonio por medio del santo Bautismo y enviarlas al cielo. No hemos podido los dos Padres que estamos aquí tantear este vado, porque sólo los dos establecimientos nos han tenido casi atados, no pudiendo salir más que lo necesario para atender á los vecinos de la Misión, y á las rancherías inmediatas de los tirurayes [...]. ${ }^{62}$

Jacinto visitóa numerosos moros en sus rancherías, llevando siempre una botella de agua para bautizar aromatizada, pues a ellos les gustaban los aromas, y así, con el pretexto de darles medicinas, los bautizaba sin que lo sospecharan. La epidemia se prolongó 4 meses, siguiéndola una oleada de viruelas negras $y$, sin haber terminado ésta aún, hubo otro azote de cólera. Se estimó que había muerto una séptima parte de la población. En esta coyuntura Bennasar subraya insistentemente en su obra que, como hemos observado en el funcionamiento de la colonia agrícola, Jacinto no se ocupaba sólo de la asistencia espiritual de los nativos, sino también de sus necesidades terrenales. Trabajó sin descanso para atender a los enfermos tanto del pueblo como de los colegios ${ }^{63}$, pero no sólo en calidad de religioso, como él mismo explicaba: «[...] en toda esta Misión hemos tenido que servir de médicos, de farmacéuticos y de enfermeros, pues carecemos de unos y de otros». ${ }^{64}$ De hecho, una de las obras más notables efectuadas por la Iglesia católica en Filipinas desde la época de la conquista fue la atención a los enfermos, dada la ausencia casi absoluta

60 «Jacinto Juanmartí a PS. Juan Ricart, Tamontaca, 4 febrero 1896», CF 9/7/27. AHSIC.

61 Sobre la figura del demonio como conspirador en la América colonial y la lucha misional contra éste, ver: Cañizares-Esguerra 2008.

62 "Jacinto Juanmartí al PS. Juan Ricart, Tamontaca, 13 enero 1883», en 1883. Cartas de los Padres de la Compañía de Jesús de Filipinas, 18811883: vol. 5, 196.

63 Bennasar 1900: 11 y 36-37.

64 «Jacinto Juanmartíal PS. Juan Ricart, Tamontaca, 13 enero 1883», en 1883. Cartas de los Padres de la Compañía de Jesús de Filipinas, 1881 1883: vol. 5, 197. de personal médico y de medicinas occidentales. ${ }^{65}$ Juanmartí tenía un botiquín bastante completo y, tras la experiencia de muchos años en Filipinas, fue adquiriendo conocimientos básicos de las enfermedades comunes del país. Como nunca hubo médico en Tamontaca, él fue el único que atendió a los enfermos. Además, también ejerció de enfermero, curando él mismo las llagas de pies y piernas de los niños, dolencia tan habitual en Filipinas. Tenía una hora concreta del día para dicha tarea, en la que se reunía con un grupo de llagosos y todos esperaban su turno. Esta labor cobró gran fama entre los moros y los cristianos de los alrededores, viniendo moros de rancherías lejanas para pedir medicinas para sus llagas. Todos sabían que el convento estaba abierto para los necesitados a cualquier hora. ${ }^{66}$ El cuidado espiritual iba, pues, de la mano del cuidado terrenal.

Por su parte, las Madres del Beaterio se ocuparon de cuidar a las niñas durante la citada epidemia. Como contaba Jacinto, «[...] han tenido también mucho que hacer y padecer y ofrecer á Dios durante esta temporada [...]; sin más médicos ni recursos que los que ellas mismas podían proporcionarles, dando en todo ejemplos de abnegación, humildad y paciencia». ${ }^{67}$

Al terminar la epidemia, Jacinto tuvo unas palabras de afecto y admiración para los nativos que constituyen otro ejemplo de la mencionada autocomplacencia de los propios misioneros:

Los más de estos, tanto niños como niñas, han dado pruebas de verdadera piedad y sentimientos cristianos durante la epidemia, ya asistiendo á sus compañeros apestados con mucha caridad, ya haciendo actos de religión, confesándose y acudiendo á Dios con mucho fervor para implorar su misericordia. ¡Cuántos de estos niños hace poco eran moros obcecados y ahora se confesaban y se acercaban á la sagrada comunión con un arrepentimiento y con un fervor que daba devoción! ${ }^{68}$

La vertiente humanitaria se evidencia también en la actuación que tuvieron tanto Juanmartí como sus compañeros durante las frecuentes hambrunas que azotaron Mindanao. En 1878 hubo una terrible en el Río Grande, y Jacinto repartió palay, dinero y ropa entre los tirurayes, tanto los que venían a Tamontaca como los que él mismo visitó en los montes "teniendo a veces que pasar la noche en el interior de los bosques sin más techo que las copas de los árboles, y sin más cama que el húmedo suelo». ${ }^{69} \mathrm{En}$ 1896 se repitió el hambre en el Río Grande y también en la costa sureste por las continuas y fuertes inundaciones, que destruyeron las cosechas de palay. Juanmartí pidió palay y arroz a Zamboanga y Manila para socorrerlos y no paró de repartir comida y ropas $^{70}$ :

65 De ahí el esfuerzo de los misioneros del archipiélago por aprender y experimentar en el ámbito médico y farmacéutico. Franciscanos, agustinos, dominicos y jesuitas se volcaron especialmente en esta tarea e incluso publicaron obras al respecto. Por ejemplo, el jesuita Paul Klein escribió Remedios fáciles para diferentes enfermedades (1712). Borges Morán 1992: 748-749.

66 Bennasar 1900: 83-84.

67 "Jacinto Juanmartí al PS. Juan Ricart, Tamontaca, 13 enero 1883», en 1883. Cartas de los Padres de la Compañía de Jesús de Filipinas, 18811883: vol. 5, 197.

68 Ibídem: 198.

69 Bennasar 1900: 22-23.

70 Ibídem: 64-65. 
La portería del convento se vio todo aquel año continuamente llena de moros, y era cosa verdaderamente edificante ver la paciencia que tenía en tratarles, en subir y bajar una y mil veces la escalera para tratar a unos y a otros, [...] aguantando, siempre con la sonrisa en los labios, las mil y una impertinencias de aquellas gentes, que ni idea tienen de lo que es educación. ${ }^{71}$

Jacinto nunca se mostraba impaciente, pese a que le interrumpieran mil veces en sus tareas. Siempre acudía allí a donde lo llamaran, siempre tenía tiempo para todos. Para Bennasar, se ganó a pulso el título de "Padre de los pobres». ${ }^{72}$ De hecho, su altruismo desenfrenado, así como su clara predilección por Tamontaca, desencadenó no pocos enojos entre sus subordinados. Las únicas críticas que le dispensaron sus compañeros derivaron en su totalidad del exceso de celo del padre por sus misiones. Estas disensiones internas las encontramos en la correspondencia de los misioneros, nunca en las obras oficiales, donde la Compañía omitía cualquier elemento embrutecedor de su imagen de fraternidad ideal. En 1895 Mariano Suárez, el misionero en Cotabato, se quejaba al superior de la Misión Filipina de que Juanmartí gastaba demasiado dinero. Dos años después, Mariano insistía en ese hecho y añadía que no había recursos para más establecimientos ni escuelas, pero que Jacinto pretendía fundar una nueva misión..$^{73} \mathrm{El}$ mismo Mariano le advirtió al superior que, aunque lo había pedido, Jacinto no le daría nada de las limosnas pendientes de llegar, sino que se las quedaría para su amada Tamontaca. Por eso le pedía que escribiera al padre y le ordenase "por caridad» que mandase ese dinero para Cotabato, porque tenía una deuda que cubrir. ${ }^{74}$ Pero lo que más disgustaba a este jesuita era que cuando en Tamontaca tenían a algún niño o adulto al que no podían curar, Jacinto se lo mandaba a Cotabato para que fuera admitido gratuitamente en la enfermería de allí:

Tengo dicho al Padre que en la Enfermería no se admite gratis a nadie, y si reciben alguno es quitando a los demás parte de su ración. A pesar de esta advertencia hace poco me mandó un hombre del pueblo para que el médico lo viese y yo procurase fuese recibido en la Enfermería. Escribí al médico y me contestó que él no podía y que esto era cosa del Pagador. Escribí a éste y me contestó 'Concedido'. Dije a un bata que acompañase al enfermo a la Enfermería y presentóse la tarjeta del Pagador. El Cabo le dijo que aquella tarjeta para él no valía nada si no recibía orden expresa del Pagador. Este Señor la dio. El Señor Pagador vino y, con mucha firmeza, me dijo en sustancia que no le mandemos más porque él tiene que abonar un tanto por sujeto y, como el que nosotros hemos mandado no es soldado, tiene que abonarlo él de su bolsillo (la estancia es una peseta diaria y a más hay que contar las medicinas).

Así que, desesperado, le preguntaba a su superior qué debía hacer, si debía escribir a unos y a otros para que se admitieran enfermos gratis o no y si desde Manila se podía disponer que se admitieran y que algún centro lo

\section{Ibídem: 66 .}

72 Ibídem: $85-86$ y 93.

73 «Mariano Suárez a PS. Juan Ricart, Cotabato, 22 enero 1895», CF 5/5/3. AHSIC; «Mariano Suárez a PS. Pío Pi, Cotabato, 7 febrero 1897», CF 1/13/3. AHSIC.

74 «Mariano Suárez a PS. Juan Ricart, Cotabato, 24 agosto 1895», CF 5/5/19. AHSIC. pagase. ${ }^{75}$ Nuestro hagiógrafo, por su parte, disculpa la fiebre humanitaria de su amigo: «era tanto lo que hacía por estos desgraciados, que hasta no faltaron algunos que lo tacharon por esa parte. ¡Ojalá mereciéremos todos esa tacha!». ${ }^{76}$

\section{EL PERFECTO JESUITA: CARÁCTER, VIRTUDES E INFLUENCIA}

La admiración de Bennasar por Juanmartí es patente y no pierde ocasión para encumbrarlo, no sólo en su obra, sino también en muchas de sus cartas. Tras la muerte de su compañero, expresaba así su profunda fascinación: «es necesario haber vivido cerca de él para saber lo que era, [...] he estado a su lado quince años y medio, y nunca he tenido de él la más mínima queja. ¡Ojalá hubiera él haber podido decir lo mismo de mí!». ${ }^{77}$ Para Bennasar, Jacinto encarnaba al perfecto jesuita:

\begin{abstract}
Verdaderamente me causa vergüenza que con tanto tiempo que he vivido a su lado no se me haya pegado ninguna de sus virtudes; quisiera Dios que, después de su muerte, sepa yo nombrarme heredero de ellas, ya que en vida no supe imitarlas. Confío asimismo que desde el Cielo continuará ayudándonos y que estará constantemente rogando a Dios derrame sus bendiciones sobre esta Misión a la que profesaba tanto cariño. Y por si acaso estuviera entretenido en el Purgatorio, ya que el Señor no admite a su presencia la más mínima mancha, roguemos por él que en vida tanto hizo por nosotros. ${ }^{78}$
\end{abstract}

Una de las aptitudes que más admiraba nuestro autor en Jacinto era su don para el mando:

No todos saben saben (sic) obrar de manera que en sus actos vayan hermanadas la suavidad y la fortaleza, virtudes tan necesarias a todos los que ejercen el cargo de Superior. A unos, una prudencia quizá mal entendida les induce a ser algo flojos en la corrección de ciertos abusos, mientras a otros la energía, tal vez con ribetes de dureza, hace que sean ásperos e indiscretos. No dudamos asegurar que en el Padre Juanmartí andaban las dos muy bien hermanadas. ${ }^{79}$

Para Bennasar no sería descabellado afirmar que si Jacinto nunca fue nombrado superior de la Misión Filipina fue porque no se encontró a nadie que pudiera substituirlo eficazmente en la difícil Tamontaca. Como hemos visto, desde sus inicios en la Compañía de Jesús ocupó cargos relevantes. Los que convivieron con él mientras fue superior en Tamontaca pudieron observar que de la misma forma que sabía presionar a alguien cuando era necesario, sabía relajarse cuando la situación era tensa en extremo, para impedir la fractura entre ambas partes, e incluso a veces optaba por retirarse sin decir palabra para dejar para el día siguiente la conversación en que haría reconocer al otro su falta. Su autoridad era incuestionable. Bennasar cuenta: «Como Superior no tenía consideraciones a nadie, y ante su autoridad pasaban todos por un mismo rasero; y de tal

\footnotetext{
75 «Mariano Suárez a PS. Pío Pi, Cotabato, 22 diciembre 1896», CF 9/12/22. AHSIC.

76 «Guillermo Bennasar a P. Provincial, Tamontaca 10 abril 1897», CF 3/16/8. AHSIC

77 Ídem.

78 «Guillermo Bennasar a PS. Pío Pi, Tamontaca 10 abril 1897», CF

79 Bennasar 1900: 76.
} 1/13/51. AHSIC. 
modo lo reconocían así todos los que lo trataban, que un Padre dijo un día: 'Creo que si el Padre General viniese aquí en clase de súbdito, lo trataría lo mismo que nosotros'». ${ }^{80}$ Pablo Pastells añade: «su gobierno era paternal, y a pesar de su carácter serio, se hacía niño cuando la ocasión se ofrecía». ${ }^{81}$ De hecho, una de sus debilidades eran los niños. Su actitud con éstos era verdaderamente paternal y, pese a su carácter serio y formal, se comportaba como un crío cuando la ocasión invitaba a ello. Siempre que se celebraban festividades principales, una vez terminaba la comida, solía irse un rato con los niños. Les repartía cigarrillos, bromeaba con ellos y, sobre todo, disfrutaba enormemente arrojándoles peladillas al suelo y viendo cómo se afanaban en recogerlas, empujándose unos a otros. Después de escenas familiares como esta, "se volvía a continuar la recreación con los nuestros, trasluciéndose en su rostro la satisfacción que sentía su corazón». ${ }^{82}$

Por otro lado, Jacinto era muy observante, y lo mismo exigía a sus subordinados. Asimismo, era intransigente con todo lo que consideraba abusos, y advertía a todo aquel que los cometía, "aunque siempre con caridad». Algunos jesuitas lo tacharon de «regañón». Bennasar no niega que era propenso a la cólera y que, a veces, «reprendía con cierta aspereza», pero aduce que "si el reprendido sabía aguantary callarse cual era su deber, poco a poco iba calmándose hasta el punto que lo que había empezado por dura reprensión terminaba en cariñosa amonestación». Jamás pasaba un mes sin que se explicaran las reglas de observancia a los hermanos y se diera la consulta y caso de conciencia con los padres de toda la residencia. Aunque valoraba mucho las excursiones de sus religiosos, no permitía que ninguno estuviera fuera cuando tocaba reunión, haciendo acortar las expediciones o incluso suprimiéndolas en caso necesario. En el caso de los niños llegó a la conclusión de que por el carácter, hábitos y educación que habían recibido en su ranchería de origen no siempre era posible lograrlo todo con cariño y amabilidad, "y que a veces se hacía indispensable el castigo, pero siempre estando bien convencido de la culpa y haciendo que ésta fuera también reconocida de los mismos que habían de ser fustigados, así es que en cuanto a esto nunca se oyó ninguna queja contra él». Al respecto, un hermano habría oído decir lo siguiente: «el Padre Juanmartí antes de castigar a uno lo piensa mucho, y sólo castiga cuando la culpa es muy segura, así es que cuando llega este caso no hay más que aguantar y tener paciencia». ${ }^{83}$ Probablemente esta obsesión por la observancia que retrata Bennasar, con la justificación del uso de la fuerza con los niños, es una exageración del hagiógrafo para acentuar la pureza de su conducta religiosa.

A Juanmartí se le atribuyen algunas de las cualidades típicas de la literatura misional moderna. A la pureza doctrinal mencionada, se sumaba la humildad, «religiosa y sin afectación ${ }^{84}$, y también el celo inquebrantable con carácter heroico: «el Padre Juanmartí solía a veces decir que cuando había necesidad de ir a algún punto no se acordaba de tener miedo, aunque el peligro fuera inminente; y así lo manifestó

\footnotetext{
80 Ibídem: 77-78.

81 Pastells 1916-1917: 232.

82 Bennasar 1900: 81.

83 Ibídem: 77 y 79-80.

84 Pastells 1916-1917: 233.
}

en distintas ocasiones». ${ }^{85}$ Pero no hallamos mención alguna de prácticas ascéticas, ayunos, falta de comida, uso de cilicios, etc., como parte de esas virtudes.$^{86}$ La vida cotidiana en las misiones filipinas del siglo XIX evidencia que, para los misioneros, el sustento ya no era sólo Dios, y que no despreciaban las necesidades terrenales. En el siglo XIX la penitencia, un elemento de tanto peso en las misiones de los siglos anteriores, fue desplazada en favor de la actividad evangelizadora y humanitaria. Aunque el misionero seguía teniendo que soportar numerosas dificultades que de algún modo representaban penitencias (largos viajes, clima hostil, geografía accidentada, oposición de los indígenas, escasez de recursos, etc) y que, por ellas, su figura seguía siendo concebida en gran medida como la de un bravo luchador con tintes martiriales, impedimentos como la escasez de alimentos, la falta de descanso y las enfermedades dejaron de percibirse como una grata mortificación para ser entendidas como una catástrofe para el avance de las misiones. ${ }^{87}$ Los misioneros de Filipinas del siglo XIX vivían y vestían con humildad y comían con frugalidad, pero nunca expresaban en sus cartas deseo alguno por sufrir carencias de este tipo, sino que pedían constantemente a su superior el envío de ropa, zapatos y otros enseres básicos que les permitieran vivir y trabajar mejor. Eran conscientes de la importancia de conservar su buena salud en la medida de lo posible. Se puede afirmar sin temor a la exageración que los jesuitas del siglo XIX eran trabajadores infatigables, pero, a diferencia de los primeros jesuitas del archipiélago, no solían obrar con imprudencia ni infravaloraban el medio hostil en el que debían laborar. ${ }^{88}$

Bennasar no olvida enfatizar el carisma y don de gentes de Juanmartí ni la estrecha relación que mantenía tanto con las autoridades nativas como con las españolas, ni el bien para las misiones que se tradujo de esa armonía, especialmente en los conflictos con la población mora. ${ }^{89}$ En el ocaso de la etapa española en Filipinas persistía en gran medida la influencia de las órdenes religiosas tanto en la administración colonial en general como en el ejercicio del poder local. ${ }^{90}$ Nuestro autor aporta numerosos ejemplos de esta injerencia. Por ejemplo, en 1885 el gobierno insular decidió que, para lograr la conquista absoluta del Río Grande, era imprescindible establecer un destacamento en Bacat y que los cañoneros navegaran periódicamente de Cotabato a Bacat y Tamontaca, y viceversa. Pero para poder llevar a cabo el proyecto de forma pacífica era necesario establecer una relación amistosa con el dato Uto. ${ }^{91}$ Bennasar presenta este proyecto como un acuerdo entre Juanmartí y el comandante general de Mindanao, Julio Seriñá, y narra las difíciles conversaciones con dicho dato, al que describe como un déspota sediento de sangre, como si su amigo hubiera sido su protagonista absoluto. Aunque el peso de Juanmartí está un tanto exagerado, son evidentes

85 Bennasar 1900: 34.

86 Betrán Moya 2009: 179.

87 Rico Callado 2003: 23-24.

88 Descalzo Yuste 2015: 346-347.

89 Bennasar 1900: 30-33 y 40-44.

90 Ver nota 23.

91 Montero y Vidal 1888: vol. II, 652-670. Para profundizar en este episodio de la historia de Mindanao y en la perspectiva mora magindanao de lucha anticolonial, ver: Ileto 1971. 
la influencia, entrega y valentía del misionero. Estas negociaciones terminaron en catástrofe para la residencia de Tamontaca. Aunque finalmente se logró llegar a un pacto de no agresión, a los pocos meses, en 1886, cuando se quiso situar el destacamento en Bacat, Uto huyó de la zona y empezó una guerra contra españoles y misioneros. La primera noche quemaron el almacén de la marina de Cotabato y el cuartel; la segunda, ardió la casa-colegio de niños de Tamontaca, el convento, la iglesia antigua, la iglesia en construcción y los camarines de palay ${ }^{92}$ :

Tuvo el Padre Juanmartí la terrible pena de ver en pocas horas reducida a cenizas aquella grandiosa casa que tanto le había costado, y en ocasión en que tan provista estaba de todo lo necesario [...], encontrándose después del incendio con unos ochenta niños sin techo bajo el cual cobijarse, ni un palmo de ropa para renovar sus vestidos, ni una ganta de palay para alimentarlos. Aquella mañana comieron todos, Padres, Hermanos y niños, de lo que de limosna les mandó el señor Diez, alférez, y Comandante entonces del Destacamento. ${ }^{93}$

Sólo quedó en pie el colegio de las niñas y casa de las Madres. Los siguientes días fueron de inquietud e inseguridad. Casi cada noche cundía el pánico al verse por los alrededores moros con fuego. Pronto acudió el comandante, que dispuso que 25 hombres con su teniente custodiaran Tamontaca, y volvió una relativa tranquilidad a la misión. No obstante, por todo el río había inseguridad. Los soldados levantaron un fuerte provisional en Bacat, y allí los atacaban los moros por las noches. Los cañoneros iban y venían por el río trayendo soldados, municiones y comida. Allí acudió Juanmartí, inquieto por los españoles heridos en la contienda, que de otro modo morirían sin ayuda espiritual, pero una de las veces fue herido de bala en una pantorrilla, de forma leve, y tuvo que ser trasladado a Cotabato para ser curado. En cuanto se recuperó, se trasladó a Tamontaca para dirigir e impulsar las obras de reconstrucción, ya iniciadas. Esta vez, por la experiencia del incendio, se decidió construir paredes de ladrillo y techos de teja en vez de poner tablas y techo de cogón. A finales de 1888 la casa-colegio estuvo terminada, y sólo entonces se emprendió la construcción de la iglesia. Desde el incendio sólo se había dispuesto de una capilla improvisada dentro del recinto de la capilla en construcción, y que había servido de iglesia, convento, colegio y hasta de cuartel durante todo el tiempo que el destacamento estuvo allí para custodiarlos. La nueva iglesia se terminó y fue bendecida el 8 de diciembre de $1889 .{ }^{94}$

Este tipo de disturbios que obligaban a volver a empezar, unidos a las ya de por si duras condiciones de vida de la misión, hicieron que siempre se dijera que los resultados de Tamontaca habían sido muy escasos, casi nulos. Bennasar, sintiendo que esa crítica recaía en Jacinto Juanmartí, quiso reivindicar su labor argumentando que los resultados fueron más de futuro que de presente y que había que haber convivido con él largos años para conocer el alcance de sus logros:

92 Bennasar 1900: 40-44; «Pablo Pastells a PS. Juan Ricart, Tamontaca, 15 febrero 1886», Cartas de los Padres de la Compañía de Jesús de Filipinas, 1885-1886: vol. 7, 51.

93 Bennasar 1900: 44-45.

94 Ibídem: $45-48$ y $51-52$.
Fue enviado a un campo lleno de maleza, espinos y abrojos, y antes de empezar la siembra tuvo que limpiar el suelo, y cuando estaba éste ya bastante limpio, y como quien dice a punto de sembrar la semilla, le sorprendió la muerte, tal vez porque no se le causara la pena de tener que abandonarlo, como por desgracia habría tenido que hacerlo, por haberlo dispuesto así la providencia. ${ }^{95}$

\section{EL JESUITA AUDAZ}

Los jesuitas fueron a menudo pioneros en el descubrimiento y exploración de zonas todavía desconocidas para los europeos y ese ha sido siempre uno de los aspectos destacados de la literatura misional. ${ }^{96}$ Bennasar no olvidó plasmar en su obra el profuso historial de exploraciones de Juanmartí, que visitó territorios todavía no colonizados en la segunda mitad del siglo XIX. No sólo propuso y organizó esas excursiones, sino que las encabezó, las repitió numerosas veces y luchó para evitar que esos descubrimientos cayeran en el olvido y para que esas tierras fueran progresivamente incorporadas al territorio español militarizado y misionado. La narración detallada de estas incursiones la encontramos en las propias cartas de Jacinto y de otros compañeros conservadas en el AHSIC o bien publicadas por la Orden. ${ }^{97}$ Sus principales exploraciones estuvieron dirigidas a dos zonas concretas. Por un lado, reconoció la costa sur del distrito de Cotabato, tanto hacia el este como hacia el oeste. ${ }^{98}$ Durante una de estas excursiones topó con los restos de la antigua fortaleza española de la Sabanilla:

Resto y grato recuerdo de los primeros españoles que dominaron este centro de Mindanao. No he visto cosa más pintoresca y hermosa que aquel rio y la vista de aquella antigua fuerza. Del pié de las murallas, que han resistido á los temblores y baibenes de más de dos siglos, sale el rio de Malabang [...]. Esta [construcción] que contiene hoy dentro de su espacio seis casas de moros, fué dirigida por nuestro Padre Melchor de Vera; se conserva intacta en la parte que mira al rio y al mar, que tiene de alto de 18 á 20 varas, pero los lados han quedado reducidos á una tercera parte y la parte de detrás está del todo arrasada. ${ }^{99}$

Por otro lado, siguió el recorrido del Río Grande hacia su origen y más allá, hasta la costa septentrional de Mindanao, y de esta forma logró unir la Residencia de Tamontaca, en el sur, con la de Tagoloan, en el norte, e iniciar el proceso de conquista de esa zona intermedia de la isla. ${ }^{100}$

95 Ibídem: 90-91.

96 Burrieza Sánchez 2007: 140-159.

97 Cartas de los PP. de la Compañía de Jesús de la Misión de Filipinas.

98 Consultar esta exploración en estas cartas de Jacinto Juanmartí: 1880. Cartas de los PP. de la Compañía de Jesús de la Misión de Filipinas, 1879-80: vol. 3, 7-17 (Tamontaca, 20 abril 1879) y 76-87 (Tamontaca, 20 agosto 1879); "Jacinto Juanmartí a PS. Juan Ricart, Tamontaca, 8 enero 1895", CF 5/5/31. AHSIC; "Jacinto Juanmartí a PS. Juan Ricart, Tamontaca, 7 febrero 1895", CF 5/5/32. AHSIC; "Jacinto Juanmartí a PS. Juan Ricart, Tamontaca, 27 junio 1895», CF 5/5/45. AHSIC; «Jacinto Juanmartí a PS. Juan Ricart, Tamontaca 4 febrero 1896», CF 9/7/27. AHSIC.

99 1880. Cartas de los PP. de la Compañía de Jesús de la Misión de Filipinas, 1879-80: vol. 3, 83.

100 Sobre la historia de la exploración del Río Grande, ver: notas 34, 35 y 36; Bernard 2002: 168-184. Sobre la incursión de Jacinto Juanmartí, además de Bernard, consultar: Bennasar 1900: 49-51 y 53-60; existen tres cartas de Jacinto Juanmartí narrando la primera excursión fallida: 1889. Cartas de los PP. de la Compañía de Jesús de la Misión de Filipinas, 
Jacinto Juanmartí inauguró su currículo explorador en 1878 y éste no se clausuró hasta 1897, sólo dos meses antes de su muerte. Pese a su entrega absoluta a Tamontaca y a la eterna escasez de tiempo de los misioneros, siempre persistió en su idea de reiniciar esas incursiones a la mínima oportunidad. En 1881 se mostraba apenado porque el trabajo sólo les había permitido realizar dos o tres excursiones, y expresaba: «lo mismo que en las excursiones de los años anteriores, aunque tenga que pasar uno por muchas fatigas y trabajos, siempre se vuelve consolado y con deseos de repetirlas muchas veces, para catequizar á tanta gente sencilla como vive en aquellas regiones ${ }^{101}$ Catorce años después, tras su enésima exploración, continuaba tan obsesionado con aquellos nativos paganos como el primer día: "me han impresionado tanto aquellos infieles que me han robado de veras el corazón para sentir sus penas y deseo intensamente que sean misionados». ${ }^{102}$ Fue en esa época cuando quedó prendado de la etnia de los tagabelíes de la costa sureste, muy presionados por los moros, cuyo bienestar le causaba profunda inquietud. ${ }^{103}$

Numerosas aventuras adornan esas excursiones. Desde el Barroco, los misioneros jesuitas habían descrito escenarios dantescos, donde la naturaleza indómita y unos indígenas salvajes y feroces se erigían en monstruos gigantescos que, pese a todo, ellos lograban vencer con elocuente heroicidad. ${ }^{104}$ Aunque Bennasar no relata escenas fantásticas ni tampoco milagros y la grandilocuencia está notablemente diluida, persiste el sentido heroico de las misiones y su percepción de sacrificio santificante. La posibilidad de sacrificar la vida en las misiones seguía siendo para los jesuitas del siglo XIX la oportunidad de culminar su entrega a Dios y al proceso evangelizador. En este sentido, tras visitar en 1895 la costa sureste, Jacinto expresaba:

No es del todo seguro ahora porque las costas están pobladas de moros y algunos de corteza amarga, pero confío en Dios nuestro Señor que no nos han de maltratar. Y en todo caso, nos puede costar el pellejo, que por cierto lo daría por muy bien empleado si con esto consiguiese que se abriese paso para el cielo a aquellos pobres infelices. ${ }^{105}$

Como en el género misional de Época Moderna, el providencialismo es un elemento clave en la narración de Bennasar. Los misioneros invocaban constantemente a Dios

1887-89: vol. 8, 138-141 (Cebú, 20 octubre 1888), 141-142 (Tamontaca, 14 noviembre 1888) y 146-148 (Tamontaca, 12 diciembre 1888); y hay cinco cartas de Juanmartí y una del misionero Eusebio Barrado donde se narra la exploración exitosa del río: 1891. Cartas de los PP. de la Compañía de Jesús de la Misión de Filipinas, 1889-91: vol. 9, 94-97 (Tamontaca, 31 mayo 1890), 98-109 (Cotabato, 1 junio 1890), 109110 (Tamontaca, 21 agosto 1891), 111-117 (Cotabato, 3 junio 1890) y 117-127 (vapor "Elcano», 3 junio 1890); 1895. Cartas de los PP. de la Compañía de Jesús de la Misión de Filipinas, 1892-94: vol. 10, 116-119 (Tamontaca, 10 diciembre 1893).

101 «Jacinto Juanmartí a PS. Juan Bautista Heras, Tamontaca, 25 enero 1881", en 1881. Cartas de los PP. de la Compañía de Jesús de la Misión de Filipinas, 1879-80: vol. 4, 135.

102 "Jacinto Juanmartí a PS. Juan Ricart, Tamontaca, 30 febrero 1895», CF 5/5/33. AHSIC.

103 «Jacinto Juanmartí a PS. Juan Ricart, Tamontaca, 7 febrero 1895 », CF 5/5/32. AHSIC.

104 Betrán Moya 2014: 185-193.

105 «Jacinto Juanmartí a PS. Juan Ricart, Tamontaca, 8 enero 1895», CF 5/5/31. AHSIC. cuando salían airosos de algún peligro, y lo mismo hacía Juanmartí, como en una ocasión en que viajaba por mar y lo alcanzó una tormenta:

[...] se perdió de vista la tierra $y$, sin saber hacia dónde íbamos, cogieron los remos para ver de contrarestar la bravura de las olas, teniendo todos el corazón oprimido por el temor de lo que nos iba a suceder. Yo me encomendé muy de veras a San Francisco Regio [...] y la Virgen Santísima, que nos oyeron. Luego, después de unas dos horas o tres de agonía mortal, amainó el tiempo y vimos la tierra. ${ }^{106}$

La fiebre de las exploraciones nunca le abandonó, pero no logró ver consolidadas sus incursiones. Aunque en diciembre de 1896 se aprobó la creación de dos misiones en la costa sur del distrito y Jacinto, exultante, confiaba en que también se aprobaría la del Río Grande ${ }^{107}$, estas expectativas se vieron truncadas por el avance de la Revolución Filipina, iniciada en el norte del archipiélago en agosto de ese mismo año, que paralizó los asuntos pendientes de aprobación en Manila. La revolución no afectó a Mindanao hasta finales de $1898^{108}$, cuando Jacinto ya había fallecido, pero sí causó profunda impresión en los misioneros. Juanmartí estuvo: «rogando a Dios nuestro Señor que nos restituya la paz perdida y que aplaste la cabeza de la hidra infernal, manifestada por esos ilusos». ${ }^{109}$

\section{OBRA}

Ya desde los inicios de la Compañía de Jesús en Filipinas los miembros de la Orden allí destinados tenían instrucciones de volcarse inmediatamente en el estudio de las lenguas nativas para poder interactuar rápidamente con los habitantes del archipiélago y lograr con mayor facilidad y eficacia su conversión al cristianismo. ${ }^{110}$ En una fecha tan tardía como 1897, el hermano Miguel Pujol insistía en que era imprescindible aprender el idioma nativo:

Porque es de grande necesidad para poder instruir a las gentes y dirigirlos a todos por el camino del Cielo. / Cuando ellos [los moros] vien (sic) que les ablan (sic) con su mismo idioma, es mucha la alegría que manifiestan, y luego se cobía (sic) amistad amigable, y de aquí se pasa a tratarles y catequizarles para ganar sus almas para Dios $[. ..]{ }^{111}$

Fiel a este principio, desde su llegada al distrito de Cotabato Jacinto se dedicó con ahínco al estudio de la lengua mora maguindanao, imprescindible para laborar

\footnotetext{
106 «Jacinto Juanmartía PS. Juan Ricart, Tamontaca, 27 junio 1895», CF 5/5/45. AHSIC.

107 «Jacinto Juanmartía PS. Pío Pi, Tamontaca, 10 diciembre 1896», CF 9/7/44. AHSIC.

108 El tradicional aislamiento de Mindanao, derivado de su lejanía de Manila, de sus diferencias étnicas y religiosas y, en definitiva, de su lento y difícil proceso de conquista, evangelización e hispanización, hizo que la revolución estallase allí de forma más tardía y con objetivos y desarrollos sustancialmente distintos a los norteños. Al respecto, ver: Arcilla 1990: 46-56; Aguilera Fernández 2015: 113-132; Schreurs 2000; ibídem 1982: 26-37.

109 «Jacinto Juanmartí a PS. Pío Pi, Tamontaca, 14 noviembre 1896», CF 9/7/42. AHSIC.

110 De la Costa 1967: 8.

111 «Miguel Pujol a PS. Pío Pi, Joló, 21 septiembre 1897», CF 1/6/29.
} AHSIC. 
en esa zona pero muy desconocida por los misioneros. No existía escrito alguno sobre esa lengua, así que su aprendizaje sólo podía ser oral. Las dudas se preguntaban a los nativos que podían aportar alguna información, pero la comunicación con ellos era tan complicada que a menudo se sacaban conclusiones erróneas. Además, existían diferencias gramaticales y de vocabulario entre los moros del alto y del bajo Río Grande. En definitiva, era una labor agotadora y desesperante, especialmente cuando se trataba de conceptos abstractos y no de objetos materiales. Saturado de tanta confusión, Jacinto empezó a redactar un catecismo en esta lengua. Al principio era sólo un manuscrito que usaban a veces los otros jesuitas, retocando palabras si así lo creían acertado, pero pronto fue evidente que era necesario que lo tuvieran no sólo los jesuitas sino también los niños de los Establecimientos, así que Juanmartí se dedicó a revisarlo y completarlo valiéndose de la ayuda de todo aquel que pudiera aportar datos fidedignos. A mediados de 1884 viajó a Manila para imprimir el catecismo en castellano y moro-maguindanao. ${ }^{112}$ Su entusiasmo al recibir al año siguiente varios ejemplares de la obra fue patente: no sólo podrían ahorrarse la confección de copias manuscritas, "que además llevaban muchos errores», sino que se impulsaría el proceso evangelizador, pues «hacen ellos mucho caso de lo que ven escrito [...]. Lo que de viva voz oyen no les hace tanto mella; viéndolo en letras de molde, lo leerán con más atención y se les grabará mejor en la inteligencia y en el corazón». ${ }^{113}$ Poco después publicó una cartilla bilingüe para los mismos moros maguindanao. ${ }^{114}$ Posteriormente se dedicó a preparar también una Historia Sagrada en castellano y moro-maguindanao ${ }^{115}$, que se publicó en 1888, y también una gramática y un diccionario moro-español y español-moro ${ }^{116}$, publicados en 1892 y 1893 respectivamente, para que los futuros misioneros pudieran formarse correctamente. ${ }^{117}$ Juanmartí no fue el primero ni el último jesuita que escribió y publicó catecismos o diccionarios en lenguas nativas filipinas. ${ }^{118}$ Sin embargo, la mayoría de esos autores se dedicaron al estudio de las lenguas de Luzón y de las Visayas, como el tagalo o el bisaya, olvidando las lenguas propias de Mindanao, tanto por la mayor pluralidad y dificultad de éstas como por el hecho de que en la zona dominada de la isla, es decir, el litoral,

\footnotetext{
112 Juanmartí 1885.

113 "Jacinto Juanmartí a PS. Juan Ricart, Tamontaca, 28 abril 1885", en 1887. Cartas de los Padres de la Compañía de Jesús de Filipinas, 18851886: vol. 7, 39-40.

114 Juanmartí 1887 (digitalizada en el AHSIC: FIL 0269).

115 Ibídem 1888 (digitalizado en el AHSIC: FIL 0272).

116 Ibídem 1982; ibídem 1893. Estas obras se conservan digitalizadas en el AHSIC (FIL 0267 y FIL 0268, respectivamente), como también sus borradores manuscritos: «Gramática del idioma moro-maguindanao por el P. Jacinto Juanmartí escrita para uso de los misioneros en el año 1887. Tamontaca». FIL 0254, y «Vocabulario español- moro maguindanao. Por el P. Jacinto Juanmartí S. J. Año 1892». FIL 0253.

117 Bennasar 1900: 38 y 61-62.

118 Ya en 1610 Cristóbal Jiménez publicó en Manila una Doctrina cristiana Rob. Bellarmini in linguam bisayam translata y posteriormente numerosos jesuitas como Paul Klein, Francisco Ignacio Alcina, Mateo Sánchez, Pedro de Estrada, Mateo Gisbert y Guillermo Bennasar (ver nota 2), entre muchos otros, elaboraron obras en lengua bisaya, tagala, tiruray, etc. Para una relación detallada consultar: De la Costa 1967: 620628 (Apéndice D); Arañas 1985: 221-228; Blake 1920: 25-70.
}

se hablaba también el bisaya. ${ }^{119}$ El mayor mérito de Jacinto Juanmartí reside, no sólo en el hecho de ser el primero en enfrentarse al desafío de elaborar las primeras obras en moro maguindanao, en una época tan tardía como el ocaso del siglo XIX, sino también en publicar cinco trabajos sobre la misma lengua.

\section{MUERTE DE UN MISIONERO Y DE SU MISIÓN}

Desde los inicios de la Compañía de Jesús la muerte de uno de sus miembros despuntaba siempre en los escritos edificantes de la Orden, especialmente si el fallecido había destacado por sus virtudes o gozado de fama de santidad. De ese modo se le convertía en un modelo a seguir. En 1900 Bennasar continuaba con este tipo de divulgación y, como ya hacía siglos antes Francisco de Borja, tercer prepósito general de la Compañía, presentaba la hora de la muerte de Jacinto Juanmartí como una recompensa del cielo y un merecido descanso por una vida de sacrificios y buenas obras ${ }^{120}$ :

Mucho había trabajado el Padre Juanmartí y Dios quería ya recompensar dichos trabajos. Su edad ya bastante avanzada, pues tenía 64 años, el mucho tiempo de país, los sufrimientos físicos y morales y otras varias causas habían ido poco a poco minando aquella naturaleza fuerte y robusta, y mucho más que él, los que le rodeaban, notaban en su persona bastante decaimiento, y que las fuerzas se le iban acabando, aunque su genio y sobre todo su celo y laboriosidad lo disimulaban bastante. ${ }^{121}$

Jacinto era consciente de que su fortaleza menguaba. En octubre de 1896 empezó a lamentarlo: «los años no me dejan fuerzas para trepar por estos montes» ${ }^{122}$, y a finales de ese mismo año incluso pidió que le mandaran un padre fuerte para poder seguir con las excursiones. ${ }^{123}$ Sin embargo, no asociaba esa creciente debilidad con el final de su vida, ni disminuyó su ritmo de trabajo en absoluto. Es más, su preocupación por los tagabelíes de la costa sureste le llevó a volver a visitarlos en febrero de 1897, sólo dos meses antes de su muerte. No fueron pocos los que le aconsejaron renunciar al viaje por las inevitables incomodidades que sufriría en su estado, pero en su ofuscación y en su creencia de gozar de buena salud no hizo caso de las advertencias y partió a visitar a sus queridos tagabelíes, sin duda ignorante de que era la última vez. ${ }^{124}$

A su regreso todos notaron su empeoramiento. Sin embargo, él siguió con sus labores, aunque haciéndose cada vez más visible su fatiga. Después de dar misa, en vez de situarse en el reclinatorio del coro para dar gracias, como siempre hacía, empezó a sentarse en el puente, donde enseguida se dormía. Uno de los signos más evidentes de su cansancio e incluso de la merma de alguna de sus facultades intelectuales fue que a veces se estiraba en los dos bancos que había en el puente, donde todos podían

\section{Combés 1897.}

120 Burrieza Sánchez 2009: 516 y 523.

121 Bennasar 1900: 69-70.

122 "Jacinto Juanmartí a PS. Pío Pi, Tamontaca, 15 octubre 1896», CF 9/7/39. AHSIC.

123 «Jacinto Juanmartí a PS. Pío Pi, Tamontaca, 24 diciembre 1896», CF 9/7/45. AHSIC.

124 Bennasar 1900: 70. 
verlo, y allí también se dormía. Este cambio de costumbres, tan en desacuerdo con su habitual modestia, discreción y actitud modélica, hizo sospechar a sus allegados que ya no era consciente de todo lo que hacía. ${ }^{125}$

El sábado 3 de abril de 1897 el padre Juanmartí escribió, de forma inusual, dos cartas brevísimas y apresuradas a Mariano Suárez, dándole instrucciones. En la primera de ellas mencionaba que el médico de Cotabato, José Blanco, le había visitado el día anterior y le había encontrado anémico, algo que según Bennasar le impresionó y le hizo pensar por primera vez que estaba gravemente enfermo. Probablemente esa repentina visión de la muerte próxima le empujó a redactar esas dos breves misivas a Mariano, afligido por el futuro de esas misiones que tanto dependían de su esfuerzo y de su mando. ${ }^{126}$ En la segunda carta, visiblemente confuso, declaraba: «no duermo nada y estoy no sé cómo».127 El día anterior sus mismos compañeros, Bennasar y Suárez, habían escrito a Pío Pi para contarle que Jacinto estaba muy enfermo desde su regreso de la excursión. Bennasar explicó que volvió con descomposición, y que ésta duró varias semanas, dejándolo "muy postrado". Después tuvo fiebre varias veces «y finalmente le ha venido un insomnio que le hace pasar las noches de claro en claro, lo que es causa de ese estado nervioso en que siempre se encuentra, y la cabeza que no sabe si es suya. Hace días que no baja sino para decir misa, ni se ocupa casi de nada». Bennasar expresó abiertamente la necesidad de buscarle un sustituto teniendo en cuenta que «no todos los que son buenos para Superiores lo son para esta Misión, pues así como ésta tiene condiciones especiales, parece que también debe tenerlas el que haya de estar al frente de ella». ${ }^{128}$ Lo mismo opinaba Suárez que, tras manifestar su temor de que Jacinto les diera un disgusto cualquier día, señaló que «al Padre convendría hacerle descansar, aunque por otra parte temo que el sacarle de Tamontaca es matarle. Si V. R. pudiese mandar un par de Padres se le podría aliviar el trabajo». El parecer del médico era que el estado del padre era grave y que lo mejor era que fuera enviado a España o por lo menos a Manila, para disponer de mayor atención médica. ${ }^{129}$ Pero Juanmartí no quiso marcharse. Como diría más tarde Bennasar: «el Padre Juanmartí (q. e. p. d.) prefirió irse al Cielo que a Manila. La elección no era dudosa». ${ }^{130}$

El domingo 4 todavía dio misa. El lunes 5 de abril quiso ir a Cotabato a ver al nuevo médico, Peralta, y seguir sus instrucciones, pues el anterior partía a Manila. Llegó a media mañana y Mariano Suárez tuvo que «ayudarle a desembarcar y ya me causó mala impresión verle tan postrado y tembloroso. Pero al verle enseguida que rezaba horas, paseando por el corredor, pensé que no estaba tan prostrado como primero había pensado». El médico le dio esperanzas y sólo quiso recetarle tónicos. Muy resuelto y

125 Ibídem: 70-71.

126 «Jacinto Juanmartí a Mariano Suárez, Tamontaca, 3 abril 1897», CF 1/13/49. AHSIC; Bennasar 1900: 71.

127 «Jacinto Juanmartí a Mariano Suárez, Tamontaca, 3 abril 1897», CF 1/13/50. AHSIC.

128 «Guillermo Bennasar a PS. Pío Pi, Tamontaca, 2 abril 1897», CF 1/13/48. AHSIC.

129 «Mariano Suárez a PS. Pío Pi, Cotabato, 2 abril 1897», CF 1/13/8. AHSIC.

130 «Guillermo Bennasar a PS. Pío Pi, Tamontaca, 29 abril 1897», CF 1/13/52. AHSIC. aliviado, Jacinto se dispuso a volver a Tamontaca, y aunque Mariano, sorprendido y alarmado, se atrevió a señalarle que quizá estaría mejor atendido en Cotabato con el médico, aquel no quiso escuchar, alegando que ya les escribiría los síntomas que fuera notando. Sin esperar más, regresó a Tamontaca. Pero el martes por la noche, a las 9, Mariano recibió carta del padre Felipe Ramo, que muy alarmado le decía que «el Padre estaba muy inquieto, que algunos ratos desvariaba y la lengua se le trababa, y así iba a prepararle para los últimos Sacramentos, y que preguntase al médico qué había que hacer». Aquella misma noche se confesó, de rodillas, y recibió la extremaunción. Se mandó llamar a los jesuitas que estaban fuera de la misión. ${ }^{131}$ Al día siguiente, 7 de abril, como suele suceder antes de la agonía última, mejoró. Desayunó en el comedor como era habitual. Bennasar cuenta:

Se confesó muy bien y recibió de rodillas y con mucha devoción el Santo Viático, después de lo cual quiso que le dejaran un rato solo para dar gracias. Aquello fue Providencia de Dios, pues no hacía doce minutos que lo había recibido cuando yo llegué de Taviram, entré a verle, hablamos un ratito, no muy largo, y estas fueron sus últimas palabras, pues después ya empezó a respirar con cierta fatiga y así, poco a poco, fue acabando, hasta que a las dos de la tarde dio su alma a Dios, como quien se queda dormido, y sin ninguno de aquellos estremecimientos que suelen notarse en los últimos momentos de la agonía. Su vida fue de un justo y su muerte de un santo. ${ }^{132}$

Bennasar prosigue su narración haciendo hincapié en la reacción de la gente:

Lo que sucedió después de su muerte fue una escena que jamás había visto, y verdaderamente conmovedora, y capaz de arrancar lágrimas al más empedernido. Apenas supieron los niños que había muerto, cuando todos rompieron en llanto de un modo desesperado. Se apercibieron las niñas del Colegio y de la escuela, y el llanto fue allí todavía mayor si cabe. Se propaga la noticia por el pueblo con la velocidad del rayo, y todos, hombres, mugeres y niños dejan sus cosas y, llorando y gritando, se dirigen al convento. No se oía más que iAy, Padre! ique se ha muerto el Padre! Si hubiera visto aquella escena sin saber la causa, habría pensando que habían entrado en el pueblo una gran partida de juramentados y que con el pánico huían todas las gentes por la parte opuesta. La escena se repitió a las cinco de la tarde al bajarlo a la Iglesia [...]..$^{133}$

A las 6 de la tarde llegó Mariano Suárez a la iglesia, y continuó el relato:

Velaron los Hermanos el cadáver y se puede decir que todos los libertos del Establecimiento, pues toda aquella noche estuve oyendo subir y bajar los chicos. Al día siguiente a las $6 \frac{1}{2}$ de la mañana empezamos el Oficio de Difuntos semitonado, el Padre Ramo, el Padre Bennasar y yo y, terminado, empecé el Santo Sacrificio de la misa y los Padres como músicos cantaron acompañados de los libertos. Después de cantarle el último

131 «Mariano Suárez a PS. Pío Pi, Cotabato, 12 abril 1897», CF 1/13/9. AHSIC.

132 «Guillermo Bennasar a PS. Pío Pi, Tamontaca, 10 abril 1897», CF 1/13/51. AHSIC.

133 Ídem. 
responso, mandé poner la tapa del ataúd. Al dar el primer martillazo hubo un Ilanto general. Aquello era conmovedor como yo no había visto jamás. No parecía sino que a cada uno de los circunstantes se le había muerto su padre o su hijo o su esposo. Todos llorábamos. ${ }^{134}$

Los vecinos del pueblo quisieron mostrar su cariño al difunto costeando una lápida de mármol para su tumba con esta inscripción: «R. P. Jacinto Juanmartí, Religioso de la Compañía de Jesús. Murió a 7 de abril de 1897. Tenía sesenta y cuatro años de edad y treinta y nueve de Compañía. Los libertos, tirurayes y vecinos del pueblo costearon esta lápida para su Padre». ${ }^{135}$

La descripción edificante de la enfermedad de Jacinto y de sus concurridos funerales sigue la tendencia de las hagiografías jesuitas modernas. Sin embargo, a diferencia de éstas, los feligreses no acudieron al entierro por su fama de santo ni por supuestos milagros, sino por la conocida humanidad y caridad del difunto para con ellos y el pueblo. La imagen que transmite Bennasar de Juanmartí es la de una vida de virtudes, tanto humanas como religiosas, pero no milagrosa. Tampoco hay menciones sobre la incorruptibilidad del cuerpo o algún otro aspecto prodigioso.

Con la muerte repentina de Jacinto, hubo que hacer frente a la dificultad de hallar un sustituto adecuado. En palabras de Mariano Suárez: "Son muy especiales las circunstancias de esta Misión y de la Casa de Tamontaca, y requieren un Padre de mucho talento y muy Santo. Si no reúne estas dos condiciones se deshará todo como la sal en el agua. A esta misión se le ha dado mucho bombo y un fracaso daría mucho que hablar». ${ }^{136}$ Por su parte, Bennasar afirmaba que el sustituto "sobre todo al principio, tendrá que andar con pies de plomo. ¡Es tan difícil parecer bueno después de uno que lo ha sido mucho!». Ciertamente hubo una gran expectación en el pueblo. ${ }^{137}$ La desmedida consagración de Jacinto a sus misiones, unida a sus dotes de mando, había hecho que absorbiera en su persona no sólo el cargo de superior de la residencia, sino todas las funciones misionales de ésta, lo que a su vez incrementó su autoridad. Mariano Suárez puso de manifiesto este hecho excepcional y único en la isla:

[...] el Padre Juanmartí absorvía en sí solo el ser Superior, Director y Cura Párroco, y digo que también hacía de Cura Párroco pues, aunque oficialmente lo era el Padre Bennasar, como ahora, éste no hacía en absoluto más que escribir las partidas y firmarlas y aun esto último lo hizo en virtud de una carta mía consultoria en que dije que, siendo oficialmente el Párroco, el Padre Bennasar no firmaba él los libros, lo que había de llamar la atención al Señor Obispo. El reunir en sí el Padre Juanmartí todas estas autoridades, hacía que la gente le respetase y mirase como al único Superior en todos los terrenos. ${ }^{138}$

134 «Mariano Suárez a PS. Pío Pi, Cotabato, 12 abril 1897», CF 1/13/9. AHSIC.

135 Pastells 1916-1917: 231-232.

136 «Mariano Suárez al PS. Pío Pi, Cotabato, 12 abril 1897», CF 1/13/9. AHSIC.

137 «Guillermo Bennasar a PS. Pío Pi, Tamontaca, 29 abril 1897», 1/13/52. AHSIC.

138 «Mariano Suárez a PS. Pío Pi, Tamontaca, 5 marzo 1898», CF 2/3/34. AHSIC.
Este «exceso» de autoridad, unido a la brillantez de Jacinto, se convertiría en un grave problema tras su repentina muerte. Mariano Suárez fue inmediatamente elegido superior interino. Un mes después, éste andaba desesperado porque seguía sin ser designado un superior definitivo. ${ }^{139}$ La antipatía de Mariano por Tamontaca era tan conocida que, en agosto, la noticia de su nombramiento definitivo provocó incluso las carcajadas de Guillermo Bennasar. ${ }^{140}$ Por su parte, Suárez, lejos de reírse, se vio invadido por un mar de temores ante el nuevo cargo que debía ejercer en una misión difícil que detestaba y con dos compañeros, Bennasar y el hermano Pérez, que según él no le tenían cariño alguno ${ }^{141}$, cosa ciertamente corroborada por el mismo Bennasar, que además muestra su desagrado por el padre Felipe Ramo ${ }^{142}$, en lo que constituye una muestra de las antipatías que existían en el seno interno de la Orden pese a la bucólica imagen presentaba oficialmente por la Compañía. Desesperado, Suárez escribió a Pío Pi para pedirle al menos el ejercicio de todas las funciones de la residencia, tal y como hacía su sucesor, porque en caso contrario se fracturarían las costumbres de la misión y él perdería toda autoridad ante los libertos, las autoridades y el pueblo en general. ${ }^{143}$ Finalmente se le relevó del cargo y el 11 de octubre de 1897 llegó al distrito Salvador Viñas como nuevo superior de la residencia. ${ }^{144}$

Sin embargo, los ecos de la revolución filipina y de la derrota de España hicieron que los moros comenzaran un progresivo ataque sobre las misiones, poniendo especial interés en el ganado y los productos agrícolas, pero también en los niños del orfanato de Tamontaca. Esto último decidió a los jesuitas a evacuar la residencia. Abandonaron el distrito en enero de 1899 en compañía de las Madres y de los niños y niñas de los Establecimientos de Tamontaca. ${ }^{145}$ Durante su ausencia, Bennasar y Suárez recibieron cartas de habitantes de la zona dándoles noticias del estado de los pueblos, pidiéndoles su pronto regreso y acordándose de Juanmartí146:

Respetable Padre en Cristo: día y noche damos las infinitas gracias a Jesús y María por los favores que nos a hecho y librarnos de la muerte y esclabitud de los moros, que si no fuese su amparo no hubiéramos llegado a estos tiempos, o tal bes que nos a librado por medio de buestras oraciones. Lo que nos hace entristecer (es) el no sabernos fijo cuando bais a venir, pero a la llegada de I(a) carta del Hermano Péres hemos leído uno por uno $\mathrm{y}$ todos hemos alegrado $\mathrm{y}$ enternecido acordando de ustedes que tanto habéis trabajado en

\footnotetext{
139 «Mariano Suárez a PS. Pío Pi, Cotabato, 2 mayo 1897», CF 1/13/10. AHSIC.

140 «Guillermo Bennasar a PS. Pío Pi, Cotabato, 31 agosto 1897», CF 1/13/26. AHSIC.

141 «Mariano Suárez a PS. Pío Pi, Cotabato, 31 agosto 1897», CF 1/13/27. AHSIC.

142 «Guillermo Bennasar a Miguel Saderra Mata, Tamontaca 15 octubre 1897», CF 1/13/61. AHSIC.

143 «Mariano Suárez a PS. Pío Pi, Tamontaca, 5 marzo 1898», CF 2/3/34. AHSIC.

144 Pastells 1916-1917: 235.

145 Sobre los disturbios acaecidos en el distrito de Cotabato en 1898-99, como ecos de la Revolución Filipina, ver: «Diario de la CasaMisión de Tamontaca». 1894-1899. FIL 0146. AHSIC; Pastells 1916-1917: 406-414; Cushner 1964: 288-295.

146 Cartas varias. CF 7/13/22-32. AHSIC.
} 
educarnos, que no hubiésemos abrido los ojos en las tinieblas y vernos la claridad ni sernos gentes espabilados sino fuese de ustedes. Esta deuda pues no sabemos cómo corresponderles y de cada bes que acordamos de ustedes brotaba las lágrimas en nuestros hojos, especialmente al difunto Padre Martí, que dio toda su bida en conbertirnos y hasta en la otra vida nos mira con hojos de compasión, y que su cadáber no quiso dejarnos en este triste pueblo (sic). ${ }^{147}$

Los jesuitas regresaron al Río Grande en 1901, pero Tamontaca estaba deshecha y perdió su posición preponderante. Cotabato pasó a ser la cabecera. No hubo más misioneros residiendo en Tamontaca, ni tampoco más orfanato. El trabajo se redujo al ámbito estrictamente pastoral. El experimento que se había desarrollado en esa misión desde 1861 terminó, pues, con la muerte de Jacinto y la revolución. En 1917 la residencia pasó a llamarse, como era realmente, Residencia de Cotabato. El jesuita Miguel A. Bernard visitó Tamontaca hacia 1950 y pudo ver la vieja lápida que marcaba la tumba de Jacinto Juanmartí. Regresó veinte años después, pero la piedra memorial había sido cubierta con una gruesa capa de hormigón. Ya no había señal alguna de que allí hubiera nadie enterrado. Preguntó a los vecinos si los huesos habían sido exhumados. Nadie supo decirle. ${ }^{148}$

\section{CONCLUSIÓN}

La literatura misional ha sido siempre un instrumento fundamental de la Compañía de Jesús para divulgar su actividad evangelizadora y enaltecer a sus miembros. El manuscrito de Guillermo Bennasar, lejos de ser un texto excepcional, responde a esta tradición largamente asentada en la Orden. Sin embargo, a diferencia de las obras de Época Moderna, el escrito de Bennasar huye en gran medida del relato maravilloso y se centra no sólo en el ensalzamiento de las virtudes de Jacinto Juanmartí como religioso y misionero, sino también en su valía como ser humano. La aparición de ese nuevo componente cualitativo está íntimamente relacionado con el cambio sufrido por el mundo misional en el siglo XIX, que deja de ser únicamente evangelizador.

Estos «Apuntes biográficos sobre el P. Jacinto Juanmartí», que nunca fueron publicados, debieron circular fácilmente dentro de la Compañía. De hecho, hasta el siglo XIX la literatura misional se difundió sobre todo en forma manuscrita ${ }^{149}$, para consumo interno de la misma Orden. Este tipo de obras siguieron teniendo como fin promocionar las vidas jesuitas para prender vocaciones y cohesionar internamente la Orden, pero también para continuar mejorando la imagen de la Compañía de Jesús y luchar contra sus detractores, especialmente tras su restauración a principios del siglo XIX. En esta línea, en 1903, sólo tres años

147 «Ignacio Loyola a Guillermo Bennasar, Tamontaca, 13 marzo 1900 », CF 7/13/31. AHSIC. El autor de esta carta fue uno de los antiguos niños del orfanato, sin que podamos saber cuál, pues varios de ellos fueron bautizados con ese nombre, como puede observarse en «Origen y progresos del Orfanotrofio de Tamontaca y Registro de libertos ingresados de uno y otro sexo que en él ingresaron desde el 9 de septiembre de 1872 hasta el 10 de octubre de 1893" y «Registro de moros que han venido a la Misión de Tamontaca (1891-1898)». FIL 0148. AHSIC.

148 Bernard 2002: 238-239.

149 Bouza 2001: 18 antes de que Bennasar terminase su obra, se publicaron las Cartas Edificantes de los misioneros de la Compañía de Jesús en Filipinas (1898-1902) en Barcelona, una obra donde aparecen cuidadosamente seleccionadas, recortadas e incluso reescritas algunas cartas de los misioneros que vivieron la Revolución Filipina, en aras de seguir proyectando la imagen del jesuita diligente, heroico e inquebrantable.

Aunque las hagiografías tienden a magnificar las vidas de sus protagonistas, es indudable el valor de la labor jesuita en Mindanao, así como la excepcionalidad de Jacinto Juanmartí en el marco filipino. Seis misioneros más murieron en 1897 en Filipinas ${ }^{150}$, pero ninguna de esas muertes suscitó tanta reacción en las misiones, ni tantos problemas para encontrarle un sustituto, ni tantos lamentos ni cartas de sus compañeros, ni mucho menos una obra sobre su vida. La historiografía ha rescatado numerosas vidas de jesuitas en la América colonial ${ }^{151}$, pero en el caso de Filipinas, más allá de los grandes cronistas de la primera etapa, como Pedro Chirino, sólo Saturnino Urios, que laboró 42 años en Mindanao durante la misma época que Juanmnartí, ha merecido recientemente la atención de los investigadores. ${ }^{152} \mathrm{El}$ resto continúan en el anonimato.

\section{FUENTES}

1864-1945. Catálogo de la Provincia de Aragón de la Compañía de Jesús (1864-1945). Barcelona-Tolosa.

1877-1895. Cartas de los PP. de la Compañía de Jesús de la Misión de Filipinas (1876-1894). Manila. 10 vols.

\section{BiBLIOgRAFÍA}

Aguilera Fernández, M. 2015. "La 'Revolución Filipina' y los jesuitas en la isla de Mindanao: el caso de la sublevación en Baganga». Historia Social 83: 113-132.

Arañas, P. G. 1985. «A note on Jesuits and Philippine Languages, 15811900». Philippine Studies 33 (2): 221-228.

Arcilla, J. S. SI. 1978. "The return of the Jesuits to Mindanao». Philippine Studies 26 (1-2): 16-34.

Arcilla, J. S. SI. 1988. «La Escuela Normal de Maestros de Instrucción Primaria». Philippine Studies 36 (1): 16-35.

Arcilla, J. S. SI. 1990. «The Philippine Revolution and the Jesuit Missions in Mindanao, 1896-1901». The Journal of History 35 (1-2): 46-56.

Bennasar, G. 1888. Catecismo de la doctrina cristiana en Castellano y Tiruray. Manila.

Bennasar, G. 1892a. Diccionario Tiruray-Español. Manila: TipoLitografía de Chofré y Compañía.

Bennasar, G. 1892b. Observaciones gramaticales sobre la lengua Tiruray. Manila.

Bennasar, G. 1892c. Catecismo histórico por el abate C. Fleury y traducido al Tiruray por un P. Misionero de la Compañía de Jesús. Manila.

Bennasar, G. 1893. Diccionario Español-Tiruray. Manila: Tipo-Litografía de Chofré y Compañía.

Bennasar, G. 1900. Apuntes biográficos sobre el P. Jacinto Juanmartí. Manila.

Bernard, M. A. 2002. "The Jesuit Exploration of the Pulangi or Río Grande de Mindanao, 1888-1890». Budhi 3: 168-184.

150 1897. Catálogo de la Provincia de Aragón de la Compañía de Jesús (1864-1945): 78.

151 Algunos ejemplos son: Coello de la Rosa 2007; Betrán Moya 2012: 117-148; Cavo 2007.

152 Ribes Iborra 2005. 
Bernard, M. A. SI. 2002a. "The Tamontaca experiment in southern Mindanao: 1861-1899». Budhi 5: 215-239.

Betrán Moya, J. L. 2009. «Unus Non Sufficit Orbis: La literatura misional jesuita del Nuevo Mundo». Historia Social 65: 167-185.

Betrán Moya, J. L. 2012. «Vidas memorables jesuitas: Juan Sebastián de la Parra, provincial del Perú (1546-1622)», en Á. Atienza López, Iglesia memorable: crónicas, historias, escritos... a mayor gloria. Siglos XVI-XVIII: 117-148. Madrid: Sílex.

Betrán Moya, J. L. 2014. “'Como corderos entre lobos hambrientos'. La literatura misional jesuita en las fronteras amazónicas del virreinato peruano entre finales del siglo XVII y comienzos del siglo XVIII». Cuadernos de Historia Moderna Anejo XIII: 185-193.

Blake, F. R. 1920. "A Bibliography of the Philippine Languages. Part 1». Journal of the American Oriental Society 40: 25-70.

Borges Morán, P. (dir.) 1992. Historia de la Iglesia en Hispanoamérica y Filipinas (siglos XVI-XIX). Madrid: Biblioteca de Autores Cristianos.

Bouza, F. 2001. Corre manuscrito. Una historia cultural del Siglo de Oro. Madrid: Marcial Pons.

Burrieza Sánchez, J. 2007. Jesuitas en Indias: entre la utopía y el conflicto. Trabajos y misiones de la Compañía de Jesús en la América Moderna. Valladolid: Univ. de Valladolid, Secretariado de Publicaciones e Intercambio.

Burrieza Sánchez, J. 2009. «Los jesuitas: de las postrimerías a la muerte ejemplar». Hispania Sacra LXI, 124: 513-544.

Cañizares-Esguerra, J. 2008. Católicos y puritanos en la colonización de América. Madrid: Marcial Pons.

Cava Mesa, B. 2001. «Misión de los padres jesuitas en el siglo XIX filipino. Memoria histórica del regreso a Mindanao y acción sociomisional», en M.a D. Elizalde, J. M. a Fradera y L. Alonso (eds.), Imperios y naciones en el Pacífico. Vol. I, La formación de una colonia: Filipinas: 619-640. Madrid: Casa Asia-CSIC. Biblioteca de Historia 43.

Cavo, A. 2007. Vida de José Julián Parreño, un jesuita habanero. Madrid: CSIC. [Ed. e intr. de M. - D. González Ripoll].

Coello de la Rosa, A. 2007. En compañía de ángeles. Vida del extático y fervoroso Padre Juan de Alloza, SJ (1597-1666). Barcelona: Ed. Bellaterra.

Combés, F. SI. 1897 [1667]. Historia de Mindanao y Joló: 1XIX (prólogo). Madrid: Impr. Viuda Minuesa de los Ríos. [Ed. de W. E. Retana y P. Pastells SI.].

Cushner, N. P. 1963. "Jesuit Reductions in the Philippines and Paraguay». Woodstock Letters 92: 223-232.

Cushner, N. P. 1964. "The Abandonment of Tamontaka Reduction (1898-1899)». Philippine Studies 12 (2): 288-295.

De la Costa, H. SI. 1967. The Jesuits in the Philippines. 1581-1768. Cambridge-Massachusetts: Harvard University Press.

De Morga, A. 1890 [1609]. Sucesos de las Islas Filipinas. París: Librería de Garnier Hermanos. [Ed. de José Rizal].

Descalzo Yuste, E. 2015. La Compañía de Jesús en Filipinas (15811768): realidad y representación. Tesis doctoral. Bellaterra.

Duré, A. y Laboa, J. M. a 1998. Atlas Histórico del Cristianismo. Madrid: San Pablo.

Elizalde Pérez-Grueso, M.a D. 2015a. «Poder, religión y control en Filipinas. Colaboración y conflicto entre el Estado y las órdenes religiosas, 1868-1898». Ayer 100: 151-176.

Elizalde Pérez-Grueso, M. a D. 2015b. «Un singular modelo colonizador el papel de las órdenes religiosas en la administración española de Filipinas, siglos XVI al XIX». Illes i imperis 17: 185-222.

Fernández Cuevas, J. SI. 1860. «Relación de un viaje de exploración a Mindanao», en 1889 Cartas de los PP. de la Compañía de Jesús de la Misión de Filipinas, 1887-1889: vol. 8, 5-61. Manila: Chofré y Compañía.

González Parrado, J. 1893. Memoria acerca de Mindanao. Manila: Ramírez y Compañía.

Guerrico, J. I. SI. 1881. Noticia de una importante obra de caridad. Rescate de niños de los moros de Mindanao y su cristiana educación en la Misión de la Compañía de Jesús. Manila: Amigos del País.

Gutiérrez, L. O. P. 1992. Historia de la Iglesia en Filipinas. 1565-1900. Madrid: Mapfre. Iglesia Católica en el Nuevo Mundo. lleto, R. C. 1971. Magindanao: 1860-1888. The Career of Datu Utto of Buayan. Ithaca, N. Y.: Cornell University.

Inarejos Muñoz, J. A. 2011. «Reclutar caciques: la selección de las élites coloniales filipinas a finales del siglo XIX». Hispania 71: 741-762.

Inarejos Muñoz, J. A. 2013. «Caciques con sotana. Control social e injerencia electoral de los eclesiásticos en las Filipinas españolas». Historia social 75: 23-40.

Jiménez Duque, B. 1974. La espiritualidad en el siglo XIX español. Madrid: Fundación Univ. Española. Univ. Pontificia de Salamanca.

Jiménez, C. 1610. Doctrina cristiana Rob. Bellarmini in linguam bisayam translata. Manila.

Juanmartí, J. 1885. Catecismo de la doctrina cristiana en castellano y en moro de Maguindanao por un misionero de la Compañía de Jesús. Manila.

Juanmartí, J. 1887. Cartilla moro-castellana para los Maguindanaos. Manila: Imprenta y Litografía de M. Pérez hijo.

Juanmartí, J. 1888. Compendio de Historia Universal desde la Creación del Mundo hasta la venida de Jesucristo y un Breve vocabulario en castellano y en moro-maguindanao. Singapur: Imprenta de Kon Yew Hean.

Juanmartí, J. 1893. Diccionario de la lengua Maguindanao. Manila: Imprenta Amigos del País.

Juanmartí, J. 1982. Gramática de la lengua de Maguindanao según se habla en el centro y en la costa sur de la isla de Mindanao. Manila: Imprenta Amigos del País.

Klein, P. SI. 1712. Remedios fáciles para diferentes enfermedades. Madrid.

López V. Á. 2004. Gregorio XVI y la reorganización de la iglesia hispanoamericana. El paso del régimen de patronato a la misión como responsabilidad directa de la Santa Sede. Roma: Pontificia Università Gregoriana. Tesi Gregoriana: Serie Storia Ecclesiastica.

Madigan, F. C. y Cushner, N. P. 1958. «Tamontaka: A Sociological experiment». The American Catholic Sociological Review XIX, 4: 322-336.

Madigan, F. C. y Cushner, N. P. 1961. «Tamontaka Reduction: A Community Approach to Mission Work». Neue Zeitchrift fur Missionwissenschaft XVII, 2: 81-94.

Montero y Vidal, J. 1888. Historia de la piratería malayo-mahometana en Mindanao, Joló y Borneo. Madrid: Impr. y fundición de Manuel Tello. 2 vols.

Nieto Aguilar, J. 1894. Mindanao. Su Historia y geografía. Madrid: Impr. del Cuerpo Adm. del Ejército.

O’Neill, C. E. SI. y Domínguez, J. M.a SI. (dirs.) 2001. Diccionario histórico de la Compañía de Jesús biográfico-temático. Madrid: Universidad Pontificia Comillas.

Pastells, P. SI. 1888. «Informe sobre la isla de Mindanao presentado al Excmo. Sr. Gobernador General de las Islas Filipinas D. Valeriano Wyler por el Superior de la Misión de la Compañía de Jesús P. Pablo Pastells», en P. Pastells, Misión de la Compañía de Jesús de Filipinas en el siglo XIX: 478-491. Barcelona: Tip. y Lib. Editorial Barcelonesa.

Pastells, P. SI. 1892. "Memoria», en 1891 Cartas de los PP. de la Compañía de Jesús de la Misión de Filipinas, 1889-1891: vol. 9, 599-667. Manila: Imprenta y Litografía M. Pérez hijo.

Pastells, P. SI. 1916-1917. Misión de la Compañía de Jesús de Filipinas en el siglo XIX. Barcelona: Tip. y Lib. Editorial Barcelonesa.

Pino Díaz, F. del 2005. "Los métodos misionales jesuitas y la cultura de 'los otros'», en J. J. Hernández Palomo y J. R. Moreno Jeria (coords.), La misión y los jesuitas en la América española, 15661767: cambios y permanencias: 48-68. Sevilla: Escuela de Estudios Hispano-Americanos.

Piqueras Villaldea, M. a I. 2002. Las comunicaciones en Filipinas durante el siglo XIX: caminos, carreteras y puentes. Madrid: Archiviana.

Puech, H. C. (dir.) 1981. Las religiones constituidas en Occidente y sus contracorrientes II. Madrid: Siglo XXI. Historia de las religiones.

Ribes Iborra, V. 2005. Padre Urios S. J. (1843-1916): misionero valenciano, filipino universal. Valencia: Edicep C. B.

Ricart, J. SI. 1883. "Informe sobre la reducción de Mindanao», en 1895 Cartas de los PP. de la Compañía de Jesús en la Misión de Filipinas, 1892-1894: vol. 10, 587-610. Manila: Establecimiento tipográfico de J. Marty. 
Rico Callado, F. L. 2003. «Las misiones interiores en España (1650 1739): una aproximación a la comunicación en el Barroco». Anales de la Universidad de Alicante 21: 189-210.

Ruiz Jurado, M. 2005. «Espíritu misional de la Compañía de Jesús», en J. J. Hernández Palomo y J. R. Moreno Jeria (coords.), La misión y los jesuitas en la América española, 1566-1767: cambios y permanencias: 17-42. Sevilla: Escuela de Estudios Hispano-Americanos.

Saderra Masó, M. SI. 1924. Misiones jesuíticas de Filipinas, 1581-1768 y 1859-1924. Manila: Universidad de Santo Tomás.

Sánchez Gómez, L. Á. 1989. «Estructura de los pueblos de indios en Filipinas durante la etapa española», en F. Rodao García (ed.), España y el Pacífico: 82-116. Madrid: Agencia Española de Cooperación Internacional.

Schreurs, P. M. S. C. 1982. "Four flags over Butuan». Philippine Quarterly of Culture and Society 10 (1-2): 26-37.
Schreurs, P. M. S. C. 2000. Angry days in Mindanao: the Philippine Revolution and the war against the U. S. in East and Northeast Mindanao, 1897-1908. Manila: National Historical Institute.

Schumacher, J. N. SI. 2002. «Ignacia del Espíritu Santo: The Historical Reliability of Her Principal Contemporary Biography». Philippine Studies 50 (3): 416-434.

Tenorio (Sigayán), J. 1892. Costumbres de los indios Tirurayes. Manila: Tipografía Amigos del País [trad. y notas de G. Bennasar].

Togores Sánchez, L. E. 2001. «La última frontera: el establecimiento de la soberanía española en el país moro», en M. a D. Elizalde, J. M. $\underline{a}$ Fradera y L. Alonso (eds.), Imperios y naciones en el Pacífico. Vol. I, La formación de una colonia: Filipinas: 675-698. Madrid: Casa Asia-CSIC. Biblioteca de Historia 43. 